Revista Española de Derecho Internacional Sección INFORMACIÓN Y DOCUMENTACIÓN DIPub Vol. 68/1, enero-junio 2016, Madrid, pp. 219-247 http://dx.doi.org/10.17103/redi.68.1.2016.4a (c) 2016 Asociación de Profesores de Derecho Internacional y Relaciones Internacionales ISSN: 0034-9380; E-ISSN: 2387-1253

\section{INFORMACIÓN Y DOCUMENTACIÓN}

\title{
A) DERECHO INTERNACIONAL PÚBLICO Y RELACIONES INTERNACIONALES
}

\author{
Selección y coordinación a cargo de \\ Luis M. Hinojosa Martínez \\ Catedrático de Derecho internacional público \\ Universidad de Granada
}

SUMARIO: 1. PLATAFORMA CONTINENTAL AMPLIADA AL OESTE DE LAS ISLAS CANARIAS: PRESENTACIÓN ESPAÑOLA ANTE LA COMISIÓN DE LÍMITES DE LA PLATAFORMA CONTINENTAL.-2. EL INFORME DE LA FISCALÍA DEL TRIBUNAL PENAL INTERNACIONAL SOBRE LA SITUACIÓN EN HONDURAS: LA INQUIETANTE CONCLUSIÓN DEL EXAMEN PRELIMINAR.-3. BOMBARDEOS EN SIRIA E IRAQ: LA APARICIÓN DE NUEVOS COMPONENTES NORMATIVOS PARA LA LICITUD O ILICITUD DEL USO DE LA FUERZA EN EL ORDEN INTERNACIONAL. - 4. DELIMITACIONES MARÍTIMAS Y TERRITORIALES EN EL ÁRTICO: DESARROLLO Y TENDENCIAS.-5. LA SENTENCIA DEL TRIBUNAL EUROPEO DE DERECHOS HUMANOS EN EL CASO VASILIAUSKAS C. LITUANIA (GS): EL GRUPO PROTEGIDO EN EL CRIMEN DE GENOCIDIO Y SU LESIÓN EN EL MARCO DEL ART. 7 DEL CONVENIO EUROPEO PARA LA PROTECCIÓN DE LOS DERECHOS Y DE LAS LIBERTADES FUNDAMENTALES.-6. LA CRISIS MIGRATORIA Y LA REINSTAURACIÓN DE LOS CONTROLES DE LAS FRONTERAS INTERIORES EN EL ESPACIO SCHENGEN.

\section{PLATAFORMA CONTINENTAL AMPLIADA AL OESTE DE LAS ISLAS CANARIAS: PRESENTACIÓN ESPAÑOLA ANTE LA COMISIÓN DE LÍMITES DE LA PLATAFORMA CONTINENTAL}

1. La cuestión de la delimitación del borde exterior de la plataforma continental sigue revestida de cierta incertidumbre jurídica y siendo objeto de consideración doctrinal, muy en especial en relación con la posibilidad de su extensión más allá de las 200 millas marinas [cfr., por ejemplo, FARAMIÑ́́N GILBERT, J. M., «Consideraciones jurídicas sobre la extensión de la plataforma continental más allá de las 200 millas marinas (algunas referencias a la plataforma continental española)», en SÁNCHEZ PA- 
TRÓN, J. M. y Juste RuIZ, J. (coords.), Derecho del mar y sostenibilidad ambiental en el Mediterráneo, Valencia, Tirant lo Blanch, 2014, pp. 59-86; ArMAS PFIRTER, F., «El límite exterior de la plataforma continental», Anuario Argentino de Derecho Internacional, 2000, pp. 235-256; J. M. TASsin, V., Les défis de l'extension du plateau continental - La consécration d'un nouveau rapport de l'État à son territoire, París, Pedone, 2011; Prescott, V. y Schofield C. (dirs.), The Maritime Political Boundaries of the World, Martinus Nijhoff, 2. ${ }^{a}$ ed., 2005, especialmente pp. 183-211 («The Continental Margin»)]. Es además una cuestión de controversia creciente, pudiéndose recordar a título de mero ejemplo el actual contencioso entre Nicaragua y Colombia, en el que el reciente pronunciamiento del Tribunal Internacional de Justicia (TIJ) de 17 de marzo de 2016 sobre su competencia da buena muestra de ello. En el caso español, pese al conocido hecho geológico de una reducida extensión de la plataforma continental, la cuestión ha cobrado también renovado protagonismo como consecuencia de las tres presentaciones realizadas durante los últimos años ante la Comisión de Límites de la Plataforma Continental (en adelante, CLPC) para lograr una prolongación más allá de las 200 millas marinas. La última de ellas ha correspondido a la solicitud de extensión al oeste de las Islas Canarias (Presentación CLPC, núm. 77), cuya presentación formal (oral) ante la CLPC tuvo lugar el pasado 26 de agosto de 2015. Parece, por ello, momento adecuado para revisitar brevemente el régimen iusinternacional existente en la materia (2 y 3), de forma que, una vez precisados el papel de la CLPC (4), el procedimiento establecido al respecto (5) y los antecedentes que afectan a España (6), nos detengamos en el concreto caso de la plataforma continental al oeste de las Islas Canarias (7), prestando atención particular a los aspectos de índole jurídica, muy en especial a las dos cuestiones a las que mayor relevancia presta la Comisión, a saber, la ausencia de controversias jurídicas con otros Estados ribereños (8) y la prestación de seguridades de que la presentación no prejuzga la situación de la delimitación con otros Estados concernidos (9). Con ello, se podrán extraer, finalmente, algunas conclusiones (10).

2. El régimen iusinternacional en materia de plataforma continental extendida ha conocido en las últimas décadas un notable desarrollo que afecta tanto al plano convencional, como al consuetudinario y jurisprudencial. En este sentido, en el plano convencional, la Convención de las Naciones Unidas sobre el Derecho del Mar (CNUDM), siguiendo un criterio diferente al adoptado en su momento por el art. 1 del Convenio de Ginebra sobre Plataforma Continental de 1958 (criterios de la profundidad y la explotabilidad), define la plataforma continental como el espacio marino que "comprende el lecho y el subsuelo de las áreas submarinas que se extienden más allá de su mar territorial y a todo lo largo de la prolongación natural de su territorio hasta el borde exterior del margen continental, o bien hasta una distancia de 200 millas marinas contadas desde las líneas de base a partir de las cuales se mide la anchura del mar territorial, en los casos en que el borde exterior del margen continental no llegue a esa distancia» (art. 76.1); es decir, se siguen los criterios geológico y de la distancia [cfr. JimÉnEz PIERNAS, C., «Régimen jurídico de los espacios marinos (III): plataforma continental, zona económica exclusiva y Estados sin litoral», en DíEZ DE VELASco, M., Instituciones de Derecho Internacional Público, Madrid, 18. ${ }^{a}$ ed., Tecnos, 2013, pp. 527551, especialmente p. 529]. No obstante, para dar satisfacción a los Estados con una plataforma geológica muy amplia, la Convención optó por una fórmula de equilibrio, de manera que esa distancia máxima pueda verse ampliada hasta las 350 millas marinas (art. 76.5 CNUDM), siempre que el margen continental se extienda más allá de las 200 millas y concurran las detalladas condiciones fijadas por la propia Convención (art. 76.2 en relación con el art. 76.4 a 6 CNUDM) (véase Hutchinson, D. N., «The Concept of Natural Prolongation in the Jurisprudence Concerning Delimitation of Conti- 
nental Shelf Areas», British Yearbook of International Law, vol. 55, 1984, pp. 133-187). Ello resulta de enorme relevancia práctica para los Estados ribereños, ya que estos ostentarían sobre la plataforma continental ampliada (o también llamada residual) los derechos de exploración y explotación de los recursos naturales con idéntico alcance que en cualquier otro área de la plataforma continental (art. 77.1 CNUDM).

3. En el plano consuetudinario, parece poder defenderse que el criterio de las 200 millas es ya expresión de Derecho consuetudinario. De hecho, la doctrina constata incluso una tendencia a la generación de una norma consuetudinaria conformada por lo esencial del contenido recogido en el (detallado) art. 76 CNUDM (REMIRo BROTONS, A. et al., Derecho Internacional, Valencia, Tirant lo Blanch, 2007, p. 942). A la par, en el plano jurisprudencial, el TIJ ha ido elaborando todo un cuerpo doctrinal en el que, de entrada, queda claro que del concepto de plataforma continental como "prolongación natural de su territorio bajo el mar» se derivan derechos para el Estado ribereño «ipso facto y ab initio en virtud de la soberanía del Estado sobre dicho territorio y por una extensión de esa soberanía en forma de ejercicio de derechos soberanos» (Sentencia de 20 de febrero de 1969, casos de la Plataforma continental del Mar del Norte, República Federal de Alemania c. Holanda y República Federal de Alemania c. Dinamarca, apdo. 19). Igualmente, se constata que en materia de delimitación el particularismo y la equidad cobran un protagonismo fundamental, que va a resultar particularmente relevante en relación con la exigencia de negociación entre los Estados concernidos por una ampliación de plataforma continental (p. ej., Sentencia de 24 de febrero de 1982, asunto de la Plataforma continental, Túnez c. Jamahiriya Arabe Libia; Sentencia de 12 de octubre de 1984, Delimitación de la frontera marítima en la región del Golfo de Maine, Canadá c. Estados Unidos; Sentencia de 10 de octubre de 2002, Frontera terrestre y marítima entre Camerún y Nigeria, Camerún c. Nigeria; Sentencia de 3 de febrero de 2009, asunto sobre la Delimitación marítima del Mar Negro, Rumanía c. Ucrania, etc.). Incluso el Tribunal Internacional de Derecho del Mar se ha visto confrontado con esta materia en su único asunto pronunciado hasta el momento sobre delimitación de espacios marinos [véase al respecto, en tono crítico, HuANG, Y. y LiAO, X., "Natural Prolongation and Delimitation of the Continental Shelf Beyond $200 \mathrm{~nm}$ : Implications of the Bangladesh/Myanmar Case», Asian Journal of International Law, vol. 4, 2014, pp. 281-307, igualmente, ElfERINK, A. G. O., «ITLOS's Approach to the Delimitation of the Continental Shelf Beyond 200 Nautical Miles in the Bangladesh/ Myanmar Case: Theoretical and Practical Difficulties», en Wolfrum, R. et al. (eds.), Liber amicorum Budslav Vukas, Martinus Nijhoff Publishers, en prensa]. A mayor abundamiento, aunque ciertamente en el ámbito de la Unión Europea la soberanía de sus Estados miembros sobre la plataforma continental es funcional y en parte se puede ver limitada por la aplicación del Derecho de la Unión (STJUE de 17 de enero de 2012, Salemink, ECLI:EU:C:2012:17), sigue correspondiendo a los Estados (y no a la Unión) la determinación de la extensión y límites de su territorio, incluida la plataforma continental (STJUE de 29 de marzo de 2007, Aktiebolaget, ECLI:EU:C:2007:195). En todo caso, para materializar esta ampliación de la plataforma continental, el Estado ribereño ha de someterse al correspondiente procedimiento ante la CLPC.

4. La CLPC es un órgano integrado en la División de Asuntos Oceánicos y de Derecho del Mar de la Secretaría General de las Naciones Unidas (DOALOS), cuya regulación específica se encuentra en el Anexo II de la Convención. Está compuesta por 21 miembros, que han de ser expertos en geología, geofísica o hidrografía y son elegidos por los Estados parte de la Convención teniendo en cuenta la necesidad de asegurar una representación geográfica equitativa, prestando sus servicios a título personal (art. 2.1 del Anexo II CNUDM). Desempeñan su labor por cinco años y pue- 
den ser reelegidos (art. 2.4 del Anexo II CNUDM). Su forma de trabajo habitual es en subcomisiones de siete miembros (art. 5 del Anexo II CNUDM). La función básica de la Comisión, dejando al margen la posibilidad de prestar asesoramiento al Estado ribereño interesado durante la preparación de los datos necesarios para elaborar la información requerida, es la de emitir las recomendaciones pertinentes sobre la pretendida plataforma continental ampliada a partir del examen de las informaciones que reciba de los Estados (art. 3.1 del Anexo II CNUDM). El procedimiento para la presentación de estas informaciones se regula en el citado Anexo de la Convención y en el Reglamento de la propia CLPC (CLCS/40/Rev.1, de 17 de abril de 2008), si bien es completado por las Directrices Científicas y Técnicas, también adoptadas por ella misma (CLCS/11, de 13 de mayo de 1999 y Corrs. 1 y 2; CLCS 11/Add 1 y Corr. 1), así como por algunas decisiones de la Reunión de los Estados parte de la Convención. Resulta, además, de utilidad el Manual de capacitación sobre el trazado de los límites exteriores de la plataforma continental más allá de las 200 millas y para la preparación de presentaciones de información a la Comisión de Límites de la Plataforma Continental, que, a petición de la Comisión, redactó DOALOS en 2006.

5. El procedimiento se iniciará por el Estado ribereño que, conforme a lo previsto en el art. 76 CNUDM, se proponga establecer el límite exterior de su plataforma continental más allá de las 200 millas marinas. Este presentará a la Comisión las características de ese límite exterior, junto con toda la información científica y técnica de apoyo que estime oportuna con arreglo a lo establecido en las Directrices Científicas y Técnicas. El Reglamento de la CLPC deja a los Estados la opción de realizar bien una presentación global conteniendo toda la información sobre la plataforma continental extendida a la que aspiran o bien presentaciones parciales sobre determinadas áreas concretas (apdo. 3 del Anexo I del Reglamento de la CLPC). En todo caso, el plazo fijado para realizar la presentación es de diez años a contar desde la entrada en vigor de la Convención para el Estado en cuestión (art. 4 del Anexo II CNUDM). No obstante, comoquiera que las Directrices Científicas y Técnicas para la presentación de la información no fueron aprobadas por la CLPC hasta el 13 de mayo de 1999, la Reunión de Estados parte de la Convención decidió que «en el caso de un Estado parte para el cual la Convención entró en vigor antes del 13 de mayo de 1999, se entendería que el plazo de diez años mencionado en el art. 4 del Anexo II de la Convención había empezado el 13 de mayo de 1999» (SPLOS/72, de 29 de mayo de 2001). Aun así, la práctica establecida por la Reunión de Estados parte es realizar dentro del plazo previsto una presentación preliminar (la llamada Información Preliminar y Descripción del Estado de Preparación), con el compromiso de llevar a cabo posteriormente la presentación definitiva (SPLOS/183, de 20 de junio de 2008). Una vez efectuada la presentación, tanto de forma escrita como en el acto de exposición formal oral, corresponde a las subcomisiones de la CLPC estudiar la información recibida y elaborar sus propuestas de recomendaciones a la Comisión, que finalmente las aprobará por una mayoría de dos tercios de los miembros presentes y votantes. A continuación, la Comisión remitirá la recomendación tanto al Secretario General de las Naciones Unidas como al Estado interesado (art. 6 del Anexo II CNUDM). La decisión de la Comisión tiene carácter de mera recomendación a los Estados ribereños sobre las cuestiones relacionadas con la determinación de los límites de exteriores de su plataforma continental; por tanto, la fijación definitiva de los límites de dicha plataforma continental ampliada corresponde al Estado concernido, tomando, eso sí, como base las recomendaciones de la Comisión (art. 76.8 CNUDM). Y, en ningún caso, esta recomendación de la Comisión prejuzga la cuestión de la delimitación de la plataforma continental entre Estados con costas adyacentes o situadas frente a frente (art. 76.10 CNUDM). 
6. En el caso de España, al margen de que la Convención entrara en vigor para nuestro país el 14 de febrero de 1997, el plazo de presentación de información concluyó, conforme a la decisión citada de la Reunión de Estados parte, el 13 de mayo de 2009. Durante ese periodo, España optó por realizar tres presentaciones parciales. La primera se hizo el 21 de agosto de 2006 (Presentación CLPC, núm. 6), afectaba al área del Golfo de Vizcaya y Mar Céltico y se realizó de manera conjunta con Francia, Reino Unido e Irlanda (en lo que se conoce como zona FISU a partir de las siglas en inglés de los cuatro Estados concernidos). Una vez materializada la presentación formal ante el plenario (CLCS/52, de 6 de octubre de 2006, apdos. 26 a 34), la CLPC emitió sus recomendaciones el 24 de marzo de 2009 (CLCS/62, de 20 de abril de 2009, apdos. 8 a 14), estando aún pendiente la conclusión de la negociación entre los cuatro Estados ribereños para proceder a la delimitación interna. La segunda tenía por objeto el área de Galicia (Presentación núm. 47), habiéndose depositado la presentación parcial en DOALOS el 11 de mayo de 2009 y realizado la exposición oral ante el plenario el 7 de abril del año siguiente (CLCS/66, de 30 de abril de 2010, apdos. 66 a 70), si bien aún no ha sido examinada por la Comisión (se encuentra en trámite de estudio por la subcomisión competente). Cabe destacar, en todo caso, que tanto España como Portugal, que realizó su correspondiente presentación el mismo día, han indicado expresamente la ausencia de controversias en el área; no en vano, se realizaron campañas oceanográficas conjuntas e incluso existe ya un Área de Interés Común (AIC). Ambos países han indicado, igualmente, la intención de efectuar la delimitación bilateral conforme a las exigencias del Derecho internacional. Y por lo que afecta a la que aquí nos ocupa, España depositó la información preliminar el 11 de mayo de 2009. Posteriormente, la presentación definitiva se materializó el 17 de diciembre de 2014 y el pasado 26 de agosto de 2015 tuvo lugar su presentación formal (oral) ante el pleno de la Comisión, en la sede de Naciones Unidas en Nueva York.

7. En efecto, por lo que específicamente concierne al área situada al oeste de las Islas Canarias, con la presentación formal realizada en agosto de 2015 concluía un largo y complejo proceso de recopilación de información para demostrar, conforme a las detalladas indicaciones recogidas en las Directrices Científicas y Técnicas de la Comisión, que la prolongación natural de la masa continental sumergida en el área al oeste de las Islas Canarias se extiende más allá de las 200 millas marinas establecidas con arreglo al criterio de la distancia, cumpliendo con la prueba de la pertenencia. De esta forma, España «considera que tiene el derecho para definir el límite exterior de su plataforma continental en el área al oeste de las Islas Canarias mediante la aplicación de las reglas descritas en los párrafos 4 a 10 del art. 76 de la Convención». Y ello es así porque España estima que «con la información científica y técnica aportada en esta Presentación parcial, puede demostrar a la Comisión que, tanto las líneas trazadas a una distancia de 60 millas marinas desde el pie del talud continental, como las líneas trazadas a una distancia en que el espesor de las rocas sedimentadas es de por lo menos el 1 por 100 de la distancia más corta desde ese punto hasta el pie del talud, se extienden más allá de las 200 millas marinas contadas desde las líneas de base a partir de las cuales se mide la anchura del mar territorial». La preparación de la referida presentación se hizo bajo la coordinación del MAEC (Comisión Internacional de Límites con Francia y Portugal y Asesoría Jurídica Internacional) y con la participación tanto de la Secretaría de Estado de Investigación del Ministerio de Economía y Competitividad (Instituto Geológico y Minero de España, Instituto Español de Oceanografía, Unidad de Tecnología Marina y Comisión de Coordinación y Seguimiento de las Actividades de Buques Oceanográficos) como del Ministerio de Defensa (Instituto Hidrográfico de la Marina). A título de ejemplo, para poner de manifiesto la entidad de 
los trabajos necesarios para la preparación de la posición española, puede indicarse que fueron precisas seis campañas oceanográficas de investigación entre 2010 y 2014, la disposición de tres buques oceanográficos españoles (Hespérides, Sarmiento de Gamboa y Miguel Oliver) y la realización de 68.338 km de batimetría con ecosondas.

8. Por lo que específicamente concierne a las cuestiones de índole jurídica, es de gran relevancia acreditar ante la Comisión dos elementos fundamentales, a saber, la ausencia de controversias jurídicas con otros Estados ribereños, así como dejar bien establecido que la presentación no prejuzga en modo alguno cuestiones relativas a la fijación de límites entre Estados (Anexo 1 del Reglamento de la Comisión). En relación con el primero de ellos, en los supuestos en que exista una controversia respecto de la delimitación, la Comisión «será informada de esa controversia por los Estados ribereños que hayan hecho la presentación» [apdo. 2.a) del Anexo I del Reglamento de la Comisión]. En el caso de la presentación sobre los límites de la plataforma continental de España al oeste de las Islas Canarias, España dejó constancia de la ausencia de controversias en la Presentación Parcial de Datos e Información (apdo. 5.1 del Resumen Ejecutivo). Además, como también es habitual en la práctica, se produjo un doble intercambio de notas verbales, todas ellas publicadas en la página web de DOALOS. Con respecto a Portugal, de igual forma a como ocurrió con la presentación de Galicia (véase supra, 6), ha quedado bien patente que no existe controversia alguna entre ambos países. Así, mediante Nota Verbal de 1 de abril de 2005, presentada por la Misión Permanente de Portugal ante Naciones Unidas, se hizo constar que «the Portuguese Government does not object to the Commission considering the submission made by the Kingdom of Spain concerning the outer limits of the continental shelf to the West of the Canary Islands». De forma paralela, la Misión Permanente de España ante Naciones Unidas envió el 10 de junio de 2009 otra Nota Verbal, en la que igualmente se afirmaba que el Gobierno de España no plantea ninguna objeción a la solicitud realizada por Portugal para que la Comisión considere la documentación de su presentación relativa al área de las islas de Madeira. Este contenido fue plenamente reiterado en otra Nota Verbal española de 7 de abril de 2015, enviada para deshacer cualquier posible malentendido provocado por una desafortunada Nota Verbal anterior. Por otro lado, en relación con Marruecos, su Gobierno presentó a DOALOS el 10 de marzo de 2015 una Nota Verbal, en la que, sin llegar a objetar la presentación española, planteaba reservas. En esencia, además de recordar la ausencia de delimitación de espacios marinos entre ambos Estados y reafirmar su posición respecto a la regla de la equidad en materia de delimitación, introducía reparos a propósito de la Ley 44/2010, de 30 de diciembre, sobre las aguas de Canarias (BOE núm. 318, de 30 de diciembre de 2010), por considerar que la «distance est mesurée en partant des lignes établies par la Loi 44/2010 sur les eaux canariennes». España, por su lado, contestó a través de otra Nota Verbal de 22 de abril de 2015, aclarando que «las líneas de base utilizadas para medir la anchura de la plataforma continental en la Presentación parcial sobre los límites de la Plataforma Continental de España al oeste de las Islas Canarias son las definidas en el Real Decreto 2510/1977, de 5 de agosto", como, de hecho, se especificaba en el punto 7.9 de la presentación. Ello no podía ser de otra forma a la vista de que la Ley 44/2010 no define líneas de base, con independencia de que algunos aspectos de la misma puedan resultar jurídicamente controvertidos. Finalmente, a raíz de ello, Marruecos volvió a enviar in extremis, apenas un mes antes del inicio de la presentación formal en Naciones Unidas, una nueva Nota Verbal de 29 de julio de 2015, enfocada en esta ocasión, de forma conjunta, a las pretensiones de ampliación de la plataforma continental de España, Portugal, Mauritania y Cabo Verde. En ella se omite cualquier referencia a las reservas sobre la Ley 44/2010 y se limita a reiterar la ausencia de delimitación entre 
los Estados concernidos y a solicitar a la Comisión que tenga en cuenta tal situación ( «à tenir dûment compte de cette situation dans l'examen des soumissions des extensions des Plateaux continentaux de l'Espagne, du Portugal, de la Mauritanie et du Cap vert»). Esta Nota no fue objeto de contestación por España, si bien lógicamente su contenido fue ampliamente respondido en la intervención oral ante la CLPC.

9. En este mismo orden de cuestiones jurídicas, resulta, en segundo lugar, también relevante dejar claro ante la Comisión que la presentación no prejuzga en modo alguno las cuestiones relativas a la fijación de límites entre Estados (cfr. CoLSON, D. A., "The Delimitation of the Outer Continental Shelf between Neighboring States», The American Journal of International Law, vol. 97, 2003, pp. 91-107; LILJEJensen, J. y Thamsborg, M., "The Role of Natural Prolongation in Relation to Shelf Delimitation Beyond 200 Nautical Miles», Nordic Journal of International Law, vol. 64, 1995, pp. 619-645; MEESE, R., «La délimitation du plateau continental audelà des 200 Miles", en Le plateau continental étendu aux termes de la Convention des Nations Unies sur le droit de la mer du 10 décembre 1982, París, Pedone, 2004, pp. 181-229). Ello es consecuencia tanto de la propia CNUDM, como del Reglamento de la Comisión. La primera deja patente que las decisiones de la CLPC tienen la naturaleza de recomendación (art. 76.8 CNUDM) y «no prejuzgan la cuestión de la delimitación de la plataforma continental entre Estados con costas adyacentes o situadas frente a frente» (art. 76.10 CNUDM). Y el segundo, además de reiterar que la competencia sobre las cuestiones relativas a las controversias que surjan en cuanto a la determinación del límite exterior de la plataforma continental reside en los Estados, recoge la exigencia de que la Comisión reciba «seguridades, en la medida de lo posible, por parte de los Estados ribereños que hayan hecho la presentación de que esta no prejuzga cuestiones relativas a la fijación de los límites entre Estados» [apdo. 2.b) del Anexo I del Reglamento de la Comisión]. En el caso que nos ocupa, así quedó oportunamente reflejado, en primer término, en la presentación depositada (apdo. 5 del Resumen Ejecutivo de la Presentación Parcial de Datos e Información), al preverse expresamente que esta no «prejuzga cuestiones relativas a la fijación de límites entre Estados». Es más, la propia presentación preliminar reconoció explícitamente que «[1]a extensión de la plataforma continental en el área de las Islas Canarias presenta dos polígonos de solapamiento con las potenciales extensiones de las plataformas continentales de terceros más allá de sus respectivas 200 millas». Así, en primer lugar, por lo que respecta al polígono norte, «el área de 350 millas marinas de las Islas Canarias se solapa con la posible determinación más allá de las 200 millas marinas de Portugal en el área de las Islas de Madeira. España y Portugal están de acuerdo en que sus respectivas presentaciones no prejuzgan el resultado final ni la delimitación lateral de sus respectivas plataformas ampliadas, que deberá ser acordada por los dos Estados en un momento ulterior». En segundo lugar, en relación con el polígono meridional, se estableció que «la posible extensión de la plataforma continental española podría superponerse con una eventual ampliación más allá de las 200 millas marinas de la plataforma continental del margen continental saharaui», añadiéndose de manera clara que la presentación «que se propone realizar España no prejuzga ni perjudica los derechos de terceros que puedan ser reclamados en su día». Nótese que, dada la delicada situación jurídica del Sáhara Occidental, se hace alusión genérica a «los derechos de terceros que puedan ser reclamados en su día», sin mayor especificación. En segundo término, esta posición se manifestó igualmente en todas las Notas Verbales enviadas por España en contestación a las previamente presentadas ante DOALOS por Portugal y Marruecos (véase supra, 7). Así, a nuestro entender, estas afirmaciones encuentran plena concordancia con lo previsto en el art. 5 del Anexo I del Reglamento de la CLPC. 
10. En suma, con la presentación formal oral del pasado 26 de agosto se ha dado un importante paso adelante en el camino hacia una posible ampliación de la plataforma continental ampliada más allá de las 200 millas marinas al oeste de las Islas Canarias. Se está, empero, aún lejos de su plena materialización. De entrada, pasarán (bastantes) años hasta que la Comisión emita las recomendaciones previstas en el art. 76.8 CNUDM, ya que se sigue el orden de recepción de las presentaciones y hay bastantes por delante de la nuestra. De momento, según comunicó formalmente la CLPC con fecha de 2 de septiembre de 2015, la presentación ha sido remitida a la subcomisión para el correspondiente estudio. A partir de ahí, cuando en su momento se cuente con las recomendaciones de la Comisión, corresponderá emprender las oportunas negociaciones con los Estados ribereños con costas adyacentes o enfrentadas para alcanzar un acuerdo sobre la delimitación final. Negociación esta que, en el caso del solapamiento con el polígono meridional, podría no resultar sencilla y, probablemente, tendría que insertarse dentro de un paquete negociador más amplio, que incluyera también otros espacios marinos diferentes aún pendientes de delimitación. Sobre esa base, España estará en situación de determinar de manera definitiva y obligatoria los límites externos de la plataforma, teniendo presentes las recomendaciones que emita la Comisión.

José Martín y PÉRez de NANClares Catedrático de Derecho internacional público de la Universidad de Salamanca Jefe de la Asesoría Jurídica Internacional del MAEC http://dx.doi.org/10.17103/redi.68.1.2016.4a.01

\section{EL INFORME DE LA FISCALÍA DEL TRIBUNAL PENAL INTERNACIONAL SOBRE LA SITUACIÓN EN HONDURAS: LA INQUIETANTE CONCLUSIÓN DEL EXAMEN PRELIMINAR}

1. La Oficina del fiscal de la Corte Penal Internacional (CPI) dirigida por la jurista de Gambia, Fatou Bensouda, en su informe del pasado 28 de octubre de 2015 con arreglo al art. 5 del Estatuto de Roma finiquitó el examen preliminar de la situación en Honduras concluyendo que no se reunían los requisitos legales para poder abrir una investigación. Las 31 comunicaciones remitidas por distintas asociaciones de derechos humanos y las tres visitas a Honduras no han bastado para poder calificar los hechos relativos al golpe de Estado de 2009 y los acaecidos en la región del Bajo Aguán, como crímenes contra la humanidad; y todo ello aun habiendo admitido la gravedad de los hechos denunciados.

2. Habida cuenta de la ratificación por Honduras del Estatuto de Roma el 1 de julio de 2002, y como es bien sabido, al amparo de lo dispuesto en su art. 13.c), el fiscal ostenta la potestad de iniciar unas investigaciones por propia iniciativa sobre la base de cualquier información que haya llegado a su conocimiento. En este asunto distintas organizaciones de derechos humanos hicieron llegar a la Oficina del fiscal de la CPI diferentes comunicaciones, siendo la primera de fecha septiembre de 2009. Atendiendo a estas denuncias el 18 de noviembre de 2010, la Fiscalía indicó que procedía a realizar un examen preliminar, el cual quedó archivado casi cinco años después. Curiosamente un día antes de la conclusión de la investigación, el 27 de octubre de 2015, la misma Oficina de Bensouda acusaba recibo de una nueva comunicación de la coordinadora general del Comité de Familiares Detenidos, en la que se comprometía a efectuar un "análisis independiente, imparcial y exhaustivo». Es más, en esa última comunicación se aportaban nuevas evidencias que venían a acreditar la comisión de 
crímenes de lesa humanidad y concurrencia de elementos para la admisibilidad y competencia de la Corte, que no han podido ser investigados con la debida diligencia.

3. Al margen de estas vicisitudes procesales, el fondo del examen preliminar que ahora queda concluso venía investigando en dos grandes apartados las graves violaciones de derechos humanos cometidas en Honduras desde 2009, distinguiendo entre lo acontecido durante el golpe de Estado en todo el país y la específica situación que padece la región del Bajo Aguán.

4. En cuanto al primer elemento contextual, el Informe de la Fiscalía ha procedido a evaluar tanto los hechos relativos al golpe de Estado de 28 de junio de 2009, como el periodo post-electoral desde la toma del poder por parte de Porfirio Lobo. Con independencia de este examen preliminar, llama poderosamente la atención el tratamiento desigual que han otorgado las Naciones Unidas (ONU) a este tipo de situaciones. Así, por ejemplo, si bien el derrocamiento de Aristide en Haití fue calificado por el Consejo de Seguridad como una amenaza a la paz y seguridad internacionales autorizando incluso el uso de la fuerza bajo el paraguas del Capítulo VII mediante la Resolución 841 (1993), las reacciones en Honduras han sido mucho más tibias. En este caso pese a que el ejército de Honduras comete un golpe de Estado, bendecido por la Corte Suprema que acaba dictando una orden de detención contra el Presidente democráticamente electo Manuel Zelaya Rosales, que es trasladado a Costa Rica, el Consejo de Seguridad no toma las mismas medidas drásticas para restablecer el orden constitucional. Ni el reconocimiento por parte de la Asamblea General de la ONU a Zelaya como Presidente legítimo, ni la suspensión de Honduras como miembro de la Organización de Estados Americanos (OEA), lograron ni la restauración del gobierno que fue elegido democráticamente, ni la responsabilidad de los golpistas y sus colaboradores.

Y es precisamente la impunidad del golpe de Estado la que provoca directamente los crímenes que son «comunicados» a la Fiscalía de La Haya. De esta forma, el nuevo ilegítimo poder ejecutivo al decretar de forma arbitraria el estado de excepción, encargando a la policía y fuerzas armadas «el velar por su observancia», acaba posibilitando la violenta y desproporcionada represión de las manifestaciones pacíficas, que se traduce en ejecuciones extrajudiciales, detenciones arbitrarias, torturas, violaciones sexuales y persecuciones. Ante la manifiesta inoperancia y apatía del poder judicial hondureño, se inicia la remisión de comunicaciones a la CPI, que finalmente abre un examen preliminar.

5. En este contexto pasa la Fiscalía a analizar si los hechos examinados integran todos aquellos elementos para que puedan ser constitutivos de crímenes contra la humanidad, lo cual anuncia debe interpretarse «de forma estricta» (párr. 76). Señala en su informe que los opositores al régimen, como tales, podían integrar el concepto de «población civil». Este grupo perfectamente distinguible de los ciudadanos partidarios del nuevo gobierno golpista presidido por Roberto Micheletti y que «no fueron objeto de represión», se puede diferenciar de las víctimas y manifestantes calificados oficialmente de «disidentes, rebeldes, alborotadores, comunistas, izquierdistas» (párr. 96), para así justificar su hostigamiento.

Asimismo, de conformidad con el art. 7 del Estatuto de Roma, los actos descritos como crimen contra la humanidad, al margen de dirigirse contra la población civil, deben cometerse como parte de un "ataque generalizados o sistemático». Y sobre este extremo, el art. 7.2.a) enuncia que: "Por "ataque contra una población civil" se entenderá una línea de conducta que implique la comisión múltiple de actos mencionados 
en el párrafo 1 contra una población civil, de conformidad con la política de un Estado o de una organización de cometer ese ataque o para promover esa política». En este sentido, desde sus inicios el informe reconoce de nuevo que la represión golpista constatada en casos de homicidios, torturas, violaciones, detenciones y atentados graves contra la integridad física «tomados en su conjunto, podrían constituir una "línea de conducta" que implicase la comisión múltiple de actos mencionados en el art. 7.1 contra una población civil» (párr. 13).

Aun así el ataque a la población civil debe poder calificarse de «generalizado o sistemático» y, en este sentido, la Fiscalía trae a colación los distintos pronunciamientos de las Salas de Cuestiones Preliminares para afirmar que esos ataques deben darse como parte de una política de Estado o de una organización siguiendo un "patrón regular» (párr. 82). Ahora bien al trasladar estos criterios al caso concreto de Honduras, los apartados preambulares del informe y sus conclusiones, estiman que no puede constatarse el carácter generalizado o sistemático de la represión golpista (párr. 141), y que «si bien parece que el régimen de facto elaboró un plan para tomar el poder y ejercer control sobre el país, el diseño de este plan y la implementación de las medidas adoptadas conforme a este no conllevó o implicó una política de cometer un ataque contra la población civil en cuestión» (párr. 14). Dicho esto parece que la Fiscalía se contradice al considerar en algunos puntos del informe que hubo una «línea de conducta» en la comisión de las graves violaciones de derechos humanos, incluso con el «establecimiento de una "sala de crisis" diseñada para planificar operaciones dirigidas a reprimir a la oposición», para más tarde asegurar que «no hubo un patrón consistente de atacar a los opositores al régimen de facto fuera del contexto de las manifestaciones» (párr. 17). Todo lo cual impide, según su criterio, la calificación de tales violaciones de un ataque de naturaleza sistemática.

A idéntica conclusión llega la Oficina de la Fiscalía en relación con el resto de hechos denunciados relativos al post-golpe y tras las elecciones de enero de 2010. Ignorando de nuevo la mencionada «línea de conducta» ya apuntada, se siguió el criterio gubernamental de la Comisión de la Verdad y Reconciliación impulsada por el gobierno de Lobo, que distingue entre dos tipos de homicidios: unos derivados del «uso excesivo y desproporcionado» por parte de las fuerzas de seguridad «en la represión de las manifestaciones»; y un segundo «vinculado a los asesinatos selectivos», realizados contra opositores destacados, defensores de derechos humanos y activistas políticos (párr. 87). Distinción que fue rechazada por las organizaciones de derechos humanos y por la otra Comisión de Verdad constituida por la sociedad civil, puesto que dicho argumentario estaba abocado a que la Fiscalía acabara concluyendo que: «La información disponible sugiere que los homicidios en cuestión podrían ser producto de la criminalidad común y el alza de las organizaciones dedicadas al narcotráfico» (párr. 119). Sin embargo el informe efectúa esta consideración final, sin determinar el origen de tal apreciación, toda vez que ni siquiera reseña el resultado de las actuaciones judiciales, de la autoría de los homicidios, de sus posibles cooperadores necesarios y otros hechos delictivos relevantes. Simplemente se expresa que antes del golpe de Estado el índice de criminalidad era alto en Honduras, debido a la debilidad de la administración de justicia; situación que se acentuó tras la quiebra constitucional y que por ello es difícil encontrar un nexo de unión entre la criminalidad y una "línea de conducta» en los términos del art. 7.2.a) del Estatuto de Roma.

6. El otro gran bloque temático que analiza el examen preliminar es el relativo a los crímenes cometidos en la región del Bajo Aguán. En este territorio la violencia se exacerbó con ocasión de las protestas campesinas y se constata que se produjeron 
asesinatos selectivos, severos castigos físicos que pudieran ser calificados como torturas, desapariciones forzadas y desalojos. En todo caso, considera la Fiscalía que tales actos tuvieron origen tanto en actuaciones de las fuerzas de seguridad del Estado, como en grupos armados privados a la orden de los grandes terratenientes.

En un ejercicio propio de la llamada «fertilización cruzada», el informe va invocando las investigaciones ya efectuadas sobre el caso por la Comisión Interamericana de Derechos Humanos para poner de manifiesto el grave problema del acaparamiento de tierras [ZAMORA CABOT, F. J., "El acaparamiento de tierras (land grabbing) y empresas multinacionales: el caso Mubende-Neumann", Papeles El Tiempo de los Derechos, 2013, núm. 5]. Se apunta a la plena participación de las personas jurídicas en la disputa sobre el derecho de las tierras que viene intensificado a su vez por la contratación de empresas de seguridad privada (párr. 51). Ahora bien, la Fiscalía precisa que el conflicto rebasa la cuestión de la disputa por las tierras, ya que las violaciones de derechos humanos en la región también vienen conectadas con actuaciones de bandas criminales pertenecientes al narcotráfico y saqueadores de plantaciones de palma africana. Siendo así el informe determina que: «Aun cuando algunos de los crímenes alegados podrían estar relacionados con disputas de tierras entre grupos campesinos, grandes terratenientes y empresas privadas, ante la falta de suficiente información sobre la existencia de nexos y rasgos comunes entre los múltiples crímenes alegados, la Fiscalía consideró que no existe fundamento razonable para creer que estos crímenes constituyen una "línea de conducta" en los términos del apartado a) del párr. 2) del art. 7 del Estatuto» (párr. 139). Por todo ello concluye que los hechos alegados no constituyen un ataque contra la población civil y consecuentemente no son constitutivos de crímenes contra la humanidad (párr. 140).

Sorprende esta conclusión que deja en una situación de total desamparo a las víctimas de toda esta región donde prosigue el conflicto. Y más aún, cuando el mismo informe ha admitido las denuncias sobre la ejecución de una "campaña de estigmatización contra los movimientos campesinos». A todo ello debe añadirse que se ha procedido a la militarización del Bajo Aguán por parte no solo de las fuerzas de seguridad hondureñas, sino que se han desplegado en la zona efectivos militares de los Estados Unidos bajo el propósito común «de proteger los intereses de las empresas privadas» (párr. 127 y nota 165 del informe). Siendo así, distintos informes comunicados a la Oficina de la Fiscalía han constatado tanto la comisión de crímenes por parte de las fuerzas de seguridad estatales (párr. 134), como «la existencia de un patrón de violencia que puede identificarse como ejecuciones del estilo de los escuadrones de la muerte» (párr. 136).

7. Como es más que obvio, las organizaciones de derechos humanos de Honduras en modo alguno están de acuerdo con esta conclusión y en una carta abierta de 30 de octubre de 2015 dirigida a la Fiscalía de la Corte Penal Internacional señalan que el informe "no es imparcial ni independiente». Se considera que los crímenes denunciados obedecen a un plan del ejecutivo hondureño y que resulta constatable una causalidad directa entre la declaración del estado de excepción y el despliegue de una política oficial represiva, cuyas medidas tuvieron por finalidad el establecer un mecanismo de control sobre la sociedad civil y, en especial, contra los opositores al régimen. Por ello estas organizaciones van a proceder a impugnar el informe de la Fiscalía al no apreciar esta evidente conexión.

En conexión con esta interpretación puede invocarse el llamado «Resumen Ejecutivo del Documento de Política General sobre Exámenes Preliminares de la Corte Penal Internacional» de noviembre de 2013, que señala en su párr. 1, que si bien las 
jurisdicciones nacionales deben poner fin a la impunidad de los crímenes previstos en el Estatuto, «la fiscalía procurará asegurarse de que se haga justicia» respecto de tales crímenes. Añade que «el examen preliminar de la información disponible debe llevarse a cabo de manera completa y exhaustiva» (punto 90). El que se haga justicia implica evitar la impunidad, lo que obliga a realizar una actividad completa que supone ante meros indicios que fundamentan la apertura de una investigación, presentar el asunto ante la Sala de Cuestiones Preliminares. Y de esta forma, conforme al art. 15.3 del Estatuto de Roma, las víctimas podrán participar en el proceso aportando observaciones ante la Sala, pudiendo así disipar las dudas ahora planteadas bajo el argumento de falta de información que continuamente esgrime el informe de la Fiscalía.

Es más, no cabe olvidar que la Fiscalía de la CPI ejerce las funciones tanto de instructor del procedimiento, dada la ausencia de un juez instructor, como de parte acusadora, lo que limita sobremanera la intervención de terceros y obliga a efectuar actuaciones exquisitas [Gómez Guillamón, R., «El fiscal en la Corte Penal Internacional», en Rodríguez-Villasante y Prieto, J. L. (coord.), El Derecho Internacional Humanitario ante los retos de los conflictos armados actuales, Madrid, Marcial Pons, 2006, pp. 205-210]. A mayor abundamiento, el mencionado Documento de Política General sobre Exámenes Preliminares (DPGEP) reafirma que el objetivo es «poner fin a la impunidad» (párr. 22) y que la evaluación no puede "predeterminarse exclusivamente bajo criterios excesivamene formalistas» (párr. 60). De esta forma, como factores a tener en cuenta en dicho análisis, se encuentran el número de víctimas directas e indirectas (párr. 62), la naturaleza de los crímenes (párr. 63), los medios empleados, existencia de un plan o abuso de poder (párr. 64) y el terror instalado (párr. 65).

Pues bien, pudiera estimarse que el presente archivo del examen preliminar en el caso de Honduras no cumple con estos mandatos, y más aún cuando otra de las líneas directrices de la razón de ser de la CPI es la de "prevenir la comisión de crímenes» (párr. 16 del DPGEP). Desde el 2009 en que se recibieron las primeras comunicaciones, hasta octubre del 2015 ha transcurrido un excesivo lapso de tiempo para que el informe resulte incompleto y no se haya dirimido con claridad el nexo de conexión causal directo entre los golpistas y los responsables de la mencionada "sala de crisis», con los hechos constitutivos de crímenes de lesa humanidad ante la total y manifiesta inactividad del poder judicial en Honduras.

En definitiva, este caso nos muestra el lado más oscuro de la real-politik en la que los grandes poderes fácticos no perdonaron al Presidente José Manuel Zelaya su política de izquierdas a nivel interno y sus alianzas exteriores manifestadas en su ingreso en el ALBA y su adhesión a la alianza regional de PetroCaribe. Lo trágico reside en que la política de los hechos consumados iniciada por el golpe de Estado ha desplegado todos sus efectos más adversos para la población civil, sin que se haya derivado responsabilidad alguna por las graves violaciones de derechos humanos. Impunidad, a la que ahora se suma la Corte Penal Internacional. Lamentablemente, la Oficina de la Fiscalía no ha aprovechado la oportunidad de este asunto con graves implicaciones de empresas privadas para dar un golpe de autoridad legal y moral, y así poder ganar un poco de crédito perdido por las reiteradas acusaciones de ser una Corte al servicio de un nuevo «colonialismo jurídico», que únicamente puede perseguir y condenar a líderes africanos.

José Elías Esteve Moltó

Universitat de València

http://dx.doi.org/10.17103/redi.68.1.2016.4a.02 


\section{BOMBARDEOS EN SIRIA E IRAQ: LA APARICIÓN DE NUEVOS COMPONENTES NORMATIVOS PARA LA LICITUD O ILICITUD DEL USO DE LA FUERZA EN EL ORDEN INTERNACIONAL}

1. Desde hace algún tiempo, la práctica internacional se empeña en modificar las normas que, a lo largo del siglo $\mathrm{xx}$, se configuraron en el marco de la prohibición del uso de la fuerza en las relaciones internacionales. A partir del bombardeo por parte de las fuerzas de la OTAN en el asunto de Kosovo, en marzo de 1999, se abrió el camino para que los Estados desdibujasen los límites de algunas de las excepciones a la prohibición, no siendo casual que, precisamente en ese periodo, apareciese, con intensidad, el concepto de «responsabilidad de proteger» en el orden jurídico internacional (véase, por todos, Díaz BARRADo, C. M., «La responsabilidad de proteger en el Derecho internacional contemporáneo: Entre lo conceptual y la práctica internacional», REEI, 2012, núm. 24). Los bombardeos por parte de las fuerzas armadas de ciertos Estados que están teniendo lugar en Siria e Iraq, sobre todo en 2015, son una prueba más de la voluntad de una parte de la comunidad internacional por recomponer las normas que regulan el uso de la fuerza en las relaciones internacionales o quizá son la expresión fidedigna de que la realidad internacional y normativa en este campo se están haciendo cada vez más complejas y diferentes al pasado.

2. La descomposición iraquí que encuentra sus orígenes, aunque no solo, en la desafortunada y, sobre todo, ilícita decisión de invadir Iraq en 2003; la guerra en Siria, que se prolonga desde 2011; y, muy en particular, la proclamación del Califato por parte del denominado Estado Islámico, en junio de 2014, están en la base de los bombardeos sobre el territorio de Siria e Iraq y condicionan mucho las posiciones tanto políticas como jurídicas que deben mantenerse en relación con las causas que legitimarían o no el uso de la fuerza. Los bombardeos sobre el territorio sirio e iraquí tienen, al menos, tres orígenes diferentes que mantienen una autonomía propia.

Por un lado, los Estados Unidos, al frente de una coalición internacional (o coaliciones), llevan a cabo la operación Resolución Inherente que «pretende reflejar la voluntad inquebrantable y el profundo compromiso de los Estados Unidos (sic) y los países aliados en la región y en todo el mundo para eliminar a los terroristas de ISIS y la amenaza que suponen para Iraq, la región y la comunidad internacional en general» (Comunicado del Mando Central estadounidense, de 15 de octubre de 2014). En el seno de esa coalición, aunque a veces con cierta autonomía, ha venido actuando también el Reino Unido con acciones armadas muy puntuales y, más en concreto, a partir de diciembre de 2015, una vez que el Parlamento británico autorizó esas acciones. Por otro lado, Rusia también decidió proceder al bombardeo del territorio sirio, lo que se ha extendido, con el tiempo, al territorio iraquí para combatir al Estado Islámico, aunque, en ocasiones, dichos bombardeos hayan tenido lugar bajo la sospecha, por parte de algunos Estados, de que los ataques rusos no tenían tan solo como objetivo el Daesh sino, también, algunos bastiones de los «rebeldes» que luchan contra el régimen de Bachar al-Asad. Por último, Francia, más allá de su colaboración con la coalición internacional, emprendió de manera autónoma bombardeos sobre el territorio sirio que se vieron incrementados una vez que se produjo, en 48 horas, la reacción del ejército francés a los atentados que tuvieron lugar en París el 13 de noviembre de 2015, y que fueron reivindicados por el Estado Islámico.

3. Si nos centramos en los bombardeos que tienen lugar con el fin de frenar el avance del Estado Islámico y de combatirlo, más allá de otros intereses que habiten en 
las decisiones que adoptan los Estados que ejecutan los bombardeos, debemos partir de dos consideraciones previas.

Primera, ninguno de los bombardeos que han tenido lugar se realizó con la autorización del Consejo de Seguridad de las Naciones Unidas. Por ello, no estamos en presencia de una de las causas que legitiman, con toda seguridad, el uso de la fuerza en las relaciones internacionales. Ni los bombardeos de Estados Unidos, ni los de Rusia ni los de Francia han contado con la autorización de este órgano y no existe, por tanto, resolución alguna que habilite el uso de la fuerza armada. No obstante, el 20 de noviembre de 2015, el Consejo de Seguridad adopta la Resolución 2249 (2015) en la que se «exhorta a los Estados miembros que tengan capacidad para hacerlo a que adopten todas las medidas necesarias, de conformidad con el derecho internacional, en particular la Carta de las Naciones Unidas y el derecho internacional de los derechos humanos, el derecho internacional de los refugiados y el derecho internacional humanitario, sobre el territorio que se encuentra bajo el control del EIIL [...] redoblen y coordinen sus esfuerzos para prevenir y reprimir los actos terroristas cometidos específicamente por el EIIL [...]».

Convendría aclarar, sucintamente, si la Resolución 2249 (2015) supone una autorización del uso de la fuerza para los bombardeos posteriores a su adopción y qué efectos produciría jurídicamente respecto a los hechos anteriores. Aunque esta reflexión desborda esta nota, está claro que antes de su adopción no produciría efecto alguno en el plano jurídico aunque pudiera ser utilizada políticamente para excusar el conjunto de los comportamientos de los Estados que llevan a cabo los bombardeos. Lo que resulta difícil determinar es si permite los bombardeos posteriores a los atentados que tuvieron lugar en París. Nada parece indicar que esta Resolución autorice el uso de la fuerza y, sobre todo, el hecho de que los Estados que llevan a cabo los bombardeos en el territorio controlado por el Daesh no alegan esta Resolución a la hora de justificar su comportamiento. El texto de la Resolución está redactado de manera ambigua, no se coloca en el marco del Capítulo VII de la Carta y, sobre todo, la práctica ulterior no confirma que los Estados la consideren como una causa que legitime el uso de la fuerza.

En esta línea, se recordaba un artículo publicado en Le Monde, en el que se decía que: "Concrètement, la Résolution 2249 ne donne pas d'autorisation légale à agir militairement en Syrie et en Irak, puisqu'elle n'est pas placée sous le chapitre VII de la Charte des Nations Unies qui prévoit l'usage de la force. Mais le langage employé dans le texte, qui stipule que "toutes les mesures nécessaires" sont permises pour combattre l'EI, laisse la place à l'interprétation, selon les diplomates français» (BoEgLIN, N., «Francia en guerra: breves apuntes desde la perspectiva del Derecho internacional», http://www. dipublico.org/103176).

Segunda, ninguno de los bombardeos que han tenido lugar puede ser enmarcado en la noción de «responsabilidad de proteger», con independencia de que los Estados, o algunos de ellos, aleguen razones humanitarias a la hora de bombardear posiciones del Estado Islámico. Con rotundidad, la acción en «responsabilidad de proteger» solo es posible si se cuenta con la autorización del Consejo de Seguridad, de tal modo que, de no ser así y en el caso de que se aleguen motivos humanitarios, estaríamos ante un supuesto clásico de las denominadas intervenciones de humanidad. Los bombardeos no han contando con dicha autorización por lo que la comunidad internacional no ocupó el lugar de ningún Estado que no protegía los derechos de su población. «En definitiva: nos inclinamos a descartar una afirmación rotunda respecto a que el Derecho internacional positivo permita un uso de la fuerza por razones de humanidad; ni 
siquiera en aquellos supuestos a los que responde la RP, sin una autorización previa del Consejo» (GutiÉRrez EsPADA, C., "Responsabilidad de proteger y el derecho de veto en el Consejo de Seguridad: algunos ejemplos recientes», Revista del IEEE, 2014, núm. 3).

4. En ausencia de una autorización del Consejo de Seguridad, solo quedarían dos eventuales causas que legitimarían el uso de la fuerza en el territorio controlado por el Daesh en Siria e Iraq, al hilo de los bombardeos que se han producido en ese territorio.

Primero, habría que comprobar si concurre o no la legítima defensa. El Gobierno francés ha alegado, en varias ocasiones, que los ataques armados contra el Daesh eran una expresión de la legítima defensa. "Nous avons frappé, il y a quelques jours et nous continuerons à le faire dans le cadre de la légitime défense de l'article 51 de la Charte des Nations unies» (BoEgLIN, N., op. cit.). A juicio del Gobierno francés, existiría una agresión armada contra Francia que coloca a este país en estado de legítima defensa. De ser así, poco cabría decir ya que la legítima defensa es, con toda seguridad, una de las causas que, en el ordenamiento jurídico internacional, legitiman el uso de la fuerza. La cuestión central es determinar si se dan o no los requisitos necesarios tanto para que el Estado francés se encuentre en estado de legítima defensa como si se cumplen las condiciones para un ejercicio apropiado de este derecho, sin entrar, como es lógico, a analizar con todo detalle las condiciones de su ejercicio.

Las claves, en el asunto que nos ocupa, radican en determinar si se produjo antes del bombardeo por parte de Francia del territorio controlado por el Estado Islámico una agresión armada contra el Estado francés, siendo así que corresponde, prima facie, a cada Estado calificar si se encuentra o no en estado de legítima defensa y que no ha habido, al respecto, ninguna intervención del Consejo de Seguridad. A la luz de la práctica, cabe apreciar que no se han producido reacciones relevantes en la comunidad internacional en contra de la intervención francesa llevada a cabo bajo la alegación del estado de legítima defensa. Esto es así, tanto antes de los atentados ocurridos en París en noviembre de 2015 como, sobre todo, con posterioridad a dichos atentados. Otra cosa distinta es afirmar, con rotundidad y en todos los casos, que la comisión de actos terroristas supone la comisión de un ataque armado o agresión armada. Nada impediría sostener que, por su envergadura y gravedad, así como por las circunstancias de su realización, determinados actos terroristas pudieran ser calificados como agresión armada pero no necesariamente cualquier acto de esta naturaleza daría lugar al estado de legítima defensa. Apreciamos en esto, un nuevo campo para la reflexión al hilo de la práctica internacional y, sobre todo, respecto a la definición como ataque armado o acto de agresión de comportamientos que, hasta ahora, no eran considerados como tales.

A ello debería añadirse si cabe la legítima defensa en respuesta a comportamientos de un ente no estatal. Sin duda, un Estado puede estimarse agresor si envía o participa con grupos irregulares en la comisión de actos que se califiquen de agresión conforme a la Resolución 3314 (XXIX) de la Asamblea General de 1974. La respuesta no sería la misma si se tratase de grupos irregulares o grupos terroristas que actuasen sin la connivencia de un Estado (SÁNChEz RodRíGuEZ, L. I., "Una cara oscura del Derecho internacional: legítima defensa y terrorismo internacional», Cursos de Derecho Internacional y Relaciones Internacionales de Vitoria-Gasteiz 2002, Vitoria, Servicio de Publicaciones de la Universidad del País Vasco, 2002, pp. 217-266). En el caso que nos ocupa, la realidad es, en esencia, inédita, pues se trata de un grupo terrorista con base territorial, lo que nos desvelaría un nuevo caso de reacción en legítima defensa. 
Aunque el Daesh no fuera considerado un Estado, sí cabría afirmar que cabe actuar en legítima defensa cuando se trata de un grupo terrorista que, habiendo cometido actos de esta naturaleza en el territorio de otro Estado y considerados ataque armado o acto de agresión, dispone de una base territorial.

Segundo, no hay duda de que el consentimiento de un Estado legitima el uso de la fuerza por parte de otro u otros Estados cuando tiene lugar en el territorio del primero y, siempre y cuando, ese consentimiento sea válido (DíAz BARRADO, C. M., El consentimiento, causa de exclusión de la ilicitud del uso de la fuerza, en Derecho internacional, Zaragoza, Prensas Universitarias, 1989). Buena parte de los bombardeos que se producen en el territorio de Siria e Iraq se llevan a cabo por Estados que alegan contar con el consentimiento bien de Siria o bien de Iraq según del lugar en el que se produzcan los ataques o bien de los dos Estados. En carta de 20 de septiembre de 2014 al Consejo de Seguridad, el Gobierno iraquí decía que «de conformidad con el derecho internacional y lo dispuesto en los acuerdos bilaterales y multilaterales pertinentes, y respetando debidamente la soberanía nacional más absoluta y la Constitución, hemos solicitado a los Estados Unidos de América que ataque los lugares donde se encuentra el EIIL y sus bastiones militares, con nuestro expreso consentimiento. El objetivo de esos ataques es poner fin a la amenaza constante para el Iraq, proteger a los ciudadanos iraquíes y, en última instancia, armar a las fuerzas iraquíes y permitirles recuperar el control de las fronteras del Iraq".

Estados Unidos y el resto de los miembros de la coalición han llevado a cabo sus acciones en territorio iraquí sobre la base del consentimiento del Gobierno de Iraq, mientras que Rusia actúa preferentemente en Siria con el consentimiento del régimen de Bachar al-Assad, como Gobierno sirio, aunque también ha actuado en territorio iraquí con el consentimiento de las autoridades de Iraq. No caben dudas de que han existido "esos consentimientos» y que, por tanto, las acciones armadas en Siria e Iraq, en esos casos, han sido autorizadas por los Gobiernos de los dos países árabes. En principio se trataría de acciones lícitas por contar con el consentimiento de las autoridades de Siria e Iraq y no sería una invención como ha sucedido en otros supuestos de la práctica internacional.

Ahora bien, la cuestión central a resolver es si se pueden considerar válidas esas autorizaciones al uso de la fuerza en un determinado territorio emitidas por Gobiernos que no controlan efectivamente el territorio en cuestión. Es decir, ¿los Gobiernos de Siria e Iraq son los Gobiernos legales, legítimos y efectivos en el territorio que está bajo el control del Estado Islámico? La respuesta a esta cuestión nos llevaría a suscitar la condición o no de Estado por parte del Califato. Políticamente, el asunto se podría despachar sosteniendo que el Estado Islámico es una «banda de criminales y terroristas» y que, por tanto, no podría ser considerado un Estado a los efectos del ordenamiento jurídico internacional. Pero lo cierto es que el Daesh tiene los atributos de un Estado por lo que una cosa sería si ostenta o no la condición de Estado y otra si debe o no ser reconocido por los Estados que conforman la comunidad internacional.

El Califato no es reconocido en la comunidad internacional y, como mucho, podría ser considerado como un grupo irregular que actúa en el territorio de dos Estados. Aún así, siempre se puede señalar que los Estados están obligados a no reconocer al Califato ya que ha surgido como consecuencia de la violación grave, masiva y sistemática de los derechos humanos y por la violación de la prohibición del uso de la fuerza en las relaciones internacionales, por lo que su creación respondería al incumplimiento de normas imperativas del Derecho internacional (MARIÑo MEnÉndez, F., Derecho Internacional Público: Parte General, Madrid, 4. ${ }^{a}$ ed., Trotta, 2005, pp. 172 y ss.). No 
obstante, por lo que nos interesa, dos cuestiones parecen ciertas: Primera, el Daesh no ha dado su consentimiento a que se realicen los bombardeos en el territorio que controla. Segunda, el consentimiento a esos bombardeos proviene de Gobiernos que no controlan efectivamente el territorio donde se producen. Con base en ello, la práctica internacional revelaría que no se puede estimar válido el consentimiento que emane de un Gobierno que no tenga el control efectivo del territorio en el cual se lleva a cabo el uso de la fuerza.

Otro enfoque distinto sería sostener que, en ningún caso, se puede estimar que el Califato es un Estado ni que tiene los atributos del mismo pues se trata, en realidad, de un mero grupo terrorista que, provisional y transitoriamente, ha ocupado parte del territorio de dos Estados que están inmersos en situaciones de conflicto interno o guerra civil. Por tanto, en el marco de la lucha contra el terrorismo internacional sería posible sostener la validez del consentimiento de los Estados en cuyos territorios (a pesar de que no los controlen efectivamente) se llevan a cabo las acciones armadas que suponen los bombardeos sobre las posiciones del Estado Islámico. Solo la práctica ulterior nos revelará si esta opción ha sido la acogida por la comunidad internacional.

5. En definitiva, aunque no pueda profundizar en cada una de las consideraciones anteriores, queda claro que se están perfilando las causas que legitiman el uso de la fuerza en las relaciones internacionales y que la lucha contra el Estado Islámico va a servir, y mucho, para determinar los límites dentro de los cuales cabría el uso lícito o ilícito de la fuerza para el ordenamiento jurídico internacional. Nuevos componentes están apareciendo en las consideraciones relativas a la licitud e ilicitud del uso de la fuerza en las relaciones internacionales.

$$
\begin{array}{r}
\text { Elena C. Díaz GaLÁN } \\
\text { Universidad Rey Juan Carlos } \\
\text { http://dx.doi.org/10.17103/redi.68.1.2016.4a.03 }
\end{array}
$$

\section{DELIMITACIONES MARÍTIMAS Y TERRITORIALES EN EL ÁRTICO: DESARROLLO Y TENDENCIAS}

1. Como punto de partida, es necesario poner de manifiesto que los Estados árticos han venido resolviendo sus controversias marítimas - solo queda pendiente una pequeña disputa territorial, relativa a la pequeña isla de Hans y próxima a su solución final- con base en el respeto del Derecho del Mar en vigor, concretamente a la Convención de las Naciones Unidas sobre el Derecho del Mar, de 1982 (CNUDM), de la que todos los Estados árticos son parte a excepción de Estados Unidos quien, no obstante, observa sus prescripciones por considerarlas parte del Derecho internacional consuetudinario. Prueba de ello es la tan mencionada Declaración de Ilulissat (2008), en la que los cinco Estados ribereños del Ártico, proclaman su compromiso político firme con el respeto a las premisas del Derecho del Mar en vigor.

2. En la región ártica solo queda pendiente una controversia territorial, que afecta a una pequeña isla situada en el Canal de Kennedy, en el Estrecho de Nares, que se disputan Canadá y Dinamarca. Ambos Estados han realizado actos de reivindicación del territorio. Las pretensiones canadienses se fundamentan en el título de la cesión de las islas del Norte Ártico - excepto Groenlandia- por Gran Bretaña en 1880, así como en el «uso y ocupación de la isla»; las danesas se basan en el descubrimiento por parte de los daneses de la isla, en 1853, así como el uso histórico que de la misma han venido haciendo las poblaciones inuit de Groenlandia. La controversia, sin embargo, 
es reciente en el tiempo, pues se remonta al momento — 1973, fecha crítica- en que Canadá y Dinamarca estaban tratando de delimitar sus respectivas plataformas continentales entre Groenlandia y Canadá. En ese momento y para no parar las negociaciones, ambos Estados decidieron trazar la línea de delimitación en la zona de bajamar de la zona sur de la isla continuando en la zona de bajamar de la zona norte de la isla. Lo que significa que cualquiera que sea la solución a la controversia, esta no afectará al fondo marino adyacente, ya dividido por tratado entre los dos Estados, ni tendrá consecuencias con respecto a las aguas, pues ambos países han utilizado la misma línea de delimitación para determinar sus respectivas áreas de pesca.

3. Por lo que se refiere a las delimitaciones marítimas, la casuística es mucho mayor. Requisito necesario para establecer los diversos espacios marítimos a que un Estado ribereño tiene derecho por aplicación de la CNUDM o del Derecho consuetudinario en la materia, es la determinación de las correspondientes líneas de base. Todos los Estados árticos excepto los Estados Unidos se han servido en la mayor parte de sus costas o en todas ellas, de líneas de base recta, haciendo uso de lo dispuesto en el art. 7 de la CNUDM. La fijación de esas líneas de base rectas ha generado, no obstante, algunas reacciones por parte de los Estados Unidos y otros Estados no árticos, que objetan las líneas de base rectas trazadas por Canadá y Rusia -las reacciones en este segundo caso, son mucho más modestas- para considerar como aguas interiores el Paso Noroeste (Canadá) y el Paso Norte (Rusia). Partiendo de las líneas de base:

- Canadá, Islandia, la Federación de Rusia y los Estados Unidos han reclamado 12 millas marinas (en adelante, m.m.) de mar territorial y 200 m.m. de Zona Económica Exclusiva (ZEE) en sus costas árticas.

- Noruega ha proclamado $12 \mathrm{~m} . \mathrm{m}$. de mar territorial en el territorio continental, Svalbard y Jan Mayen. 200 m.m. de ZEE en torno al territorio continental. 200 m.m. de Zona Exclusiva de Pesquerías alrededor de Jan Mayen y 200 m.m. de Zona de Protección de Pesquerías de Pesquerías alrededor de Svalbard. La Zona de Protección de Pesquerías alrededor de Svalbard es contestada por Estados parte en el Tratado de París de 1920 —entre ellos, España—, que regula el peculiar régimen de las Islas Svalbard.

- Dinamarca estableció una ZEE de 200 m.m. en torno a Groenlandia y en torno a las Islas Feroe.

- Canadá tiene una Zona de Prevención de la Contaminación Marina de 200 m.m. en aplicación de la denominada «excepción ártica» del art. 234 de la CNUDM.

4. Se pueden considerar resueltas en el Ártico, las siguientes delimitaciones marítimas:

- Delimitación entre Canadá y Dinamarca. En 1973 ambos países acordaron dividir sus respectivas plataformas continentales y zonas de pesca utilizando la línea de equidistancia y dejando un espacio sin definir relativo a la isla de Hans, como se ha mencionado.

- Delimitación entre Rusia y Estados Unidos. En el Tratado del Mar de Bering de 1990 los dos países ribereños - Estados Unidos y Rusia- acordaron la delimitación de sus respectivos espacios marítimos en el Mar de Bering, en el Mar de Chukchi y en el Estrecho de Bering. La línea está basada en la trazada en el Tratado por el que Estados Unidos adquiere Alaska de Rusia en 1867. En la opinión pública soviética, el Tratado fue ampliamente rechazado pues se negoció en un momento de debilidad de la política exterior soviética, lo que determina que la línea de demarcación en el Mar de Bering se oriente hacia el oeste de lo que debería ser la línea de equidistancia, atribuyendo más espacios a Estados Unidos. Ello ha determinado que el Tratado no esté en vigor entre ambos Estados, pues nunca fue ratificado por la Federación de Rusia, 
si bien ambas partes se atienen a lo dispuesto en el mismo — como así lo hizo constar la Federación de Rusia en su solicitud de plataforma continental extendida ante la Comisión de Límites de la Plataforma Continental (CLPC), en 2001—. El Tratado de Bering introduce algunas novedades interesantes como las "áreas especiales», zonas en las que se combina la jurisdicción de ambos países en sus respectivas ZEE, un ejemplo de cooperación entre Estados.

- Dinamarca-Islandia-Noruega (Jan Mayen): el Gobierno de Noruega incorporó formalmente la Isla de Jan Mayen a su soberanía en 1930. En 1993, en el asunto de la delimitación entre Groenlandia y Jan Mayen (Dinamarca c. Noruega), la Corte Internacional de Justicia (CIJ) consideró, a instancias de Dinamarca, que para determinar la delimitación marítima entre ambos Estados había que tener en cuenta circunstancias especiales para lograr un resultado equitativo: la mayor magnitud de la costa de Groenlandia era una circunstancia especial que obligaba a trazar la frontera marítima más cercana a Jan Mayen. Ya en 1981, Noruega e Islandia habían concluido un tratado donde se reconocía que la ZEE y la plataforma continental de Islandia se extendía en toda su amplitud a las 200 m.m. entre Jan Mayen e Islandia. Asimismo otorgaba a Noruega derechos para participar en un 25 por 100 en la exploración de los depósitos de gas y petróleo de la plataforma continental islandesa y viceversa por lo que se refiere a los derechos de Islandia en la plataforma continental noruega de Jan Mayen. Asimismo, el Tratado ya preveía un sistema novedoso por el que se necesitaban acuerdos conjuntos para explotar los recursos de gas o petróleo que se encontraban repartidos entre las plataformas de ambos Estados. En 2008 los dos países adoptaron marcos de cooperación más extensos, sobre todo por lo que se refiere a la explotación de los hidrocarburos.

- Tratado de Delimitación del Mar de Barents entre la Federación de Rusia y Noruega, de 2010. Durante alrededor de tres décadas, Noruega y Rusia discutieron su soberanía sobre una parte del Mar de Barents. En 1996 y 1997 primero Noruega y luego Rusia, ratificaron la CNUDM. Ya en 1975, ambos países concluyeron un Acuerdo sobre Cooperación de sus Industrias Pesqueras que establecía una Comisión Conjunta de Pesquerías. En 1976, mediante otro acuerdo bilateral, se afirmaba que ambos países tenían jurisdicción pesquera hasta las $200 \mathrm{~m}$.m. y se reconocían acceso mutuo a sus respectivas ZEE. En 1978, ambos países concluyen el denominado «Acuerdo de la Zona Gris», para regular las pesquerías allí donde sus reclamaciones se solapaban, reconociéndose jurisdicción recíproca sobre sus buques y los de los terceros Estados a los que respectivamente hubieran autorizado a faenar allí. Quedaba una zona de alta mar por delimitar y en 1999, Noruega, Rusia e Islandia concluyen el «Acuerdo de Loophole», por el que se reconoce el derecho de pesca a Islandia en las ZEE noruegas y rusas. A cambio, Noruega obtenía acceso a la ZEE de Islandia y Rusia obtenía un pago económico. Noruega y Rusia acordaron posponer toda actividad en la zona en conflicto relativa a la explotación de gas o petróleo, pero en 2010 ambos países logran acordar una delimitación marítima única para la ZEE y la plataforma continental. Especialmente novedoso en el Tratado es el régimen de cogestión de los depósitos de hidrocarburos repartidos en una misma bolsa en las plataformas continentales de ambos países, asimismo se establece un régimen de cogestión de las pesquerías tal y como se venía desarrollando.

- Como se señalará más adelante, Noruega presentó su solicitud de plataforma continental extendida ante la CLPC en 2006 y, desde abril de 2009, ha sido el primer país en obtener recomendaciones de la CLPC, que está implementando.

5. Son delimitaciones en curso pero no completadas, las siguientes:

- Tratado de delimitación de 2006 entre Dinamarca (Groenlandia) y Noruega en las Islas Svalbard. Este Tratado de delimitación usa la línea de equidistancia. Al con- 
cluir el tratado, Dinamarca reconoce implícitamente la pretensión noruega de que las Svalbard generan una ZEE y plataforma continental, algo que disputan algunas otras de la partes en el Tratado de París de 1920. El Tratado de delimitación, por lo demás, prevé formas de cooperación entre ambos países por lo que se refiere a los depósitos minerales existentes en ambas plataformas continentales. Existe una zona de plataforma continental más allá de las $200 \mathrm{~m}$.m. donde las pretensiones de ambas partes se solapan, pero estas, en sus respectivas solicitudes ante la CLPC, han acordado que serán resueltas por negociaciones entre las partes.

- Norte del Mar de Lincoln (Canadá-Dinamarca). En noviembre de 2012 ambos países anunciaron un acuerdo tentativo sobre la zona de plataforma continental más allá de las 200 m.m. basado en el principio de equidistancia, sin embargo será necesario el acuerdo entre las partes teniendo en cuenta que Dinamarca incluyó el Polo Norte en su solicitud de plataforma continental extendida de 2014 ante la CLPC, lo que sin duda se solapará con la petición canadiense cuando esta tenga lugar.

- Mar de Beaufort (Canadá-Estados Unidos). La controversia se plantea en la plataforma continental de la costa de Alaska adyacente a la costa de la región canadiense de Yukon y del archipiélago canadiense. Canadá sustenta su reclamación en el Tratado de 1825 entre Rusia y Gran Bretaña, que establecía el meridiano 141 de longitud Oeste como criterio de delimitación. Estados Unidos alega que la línea divisoria debe de ser perpendicular a la costa hasta una distancia de 200 m.m., siguiendo una línea equidistante de la costa. Esta diferencia crea una cuña que es reclamada por ambas naciones y en la que parecen existir importantes reservas de petróleo. Sin embargo, la postura respectiva de cada Estado es beneficiosa para recíprocamente en lo que se refiere a sus respectivas plataformas continentales extendidas en la zona.

6. En aplicación del art. 76 de la CNUDM, los Estados ribereños que logren probar con datos científicos ante la CLPC que el borde exterior de su plataforma continental se extiende más allá de las 200 m.m., pueden reclamar derechos de soberanía para la exploración y explotación de los recursos existentes en dicho espacio. Dadas las previsiones relativas a la existencia de múltiples riquezas escondidas en los fondos del Océano Ártico, así como la fecha límite para la reclamación de tales plataformas extendidas, no es de extrañar que todos los Estados ribereños de este océano se hayan lanzado a solicitar ampliaciones de sus respectivas plataformas. Ahora bien, la delimitación de las respectivas plataformas continentales de los Estados árticos en dicho océano resulta un tanto compleja en la medida en que hay múltiples peticiones que se solapan o que es previsible que lo hagan:

- Canadá, la Federación de Rusia y Dinamarca consideran que las cordilleras sumergidas de Lomonosov y Alpha Meneleyev son parte de su plataforma continental extendida, lo que da lugar a solapamientos inevitables en sus peticiones de plataforma continental extendida.

- Rusia fue el primer país del mundo en presentar su solicitud ante la CLPC, en 2001, incluyendo en la misma, dichas cordilleras. En su solicitud revisada de 2015, Rusia sigue reclamando una parte sustancial de plataforma continental frente a los otros Estados.

- En su solicitud de 2014 ante la CLPC, Dinamarca hace constar que las eventuales recomendaciones de la CLPC serán sin perjuicio de la delimitación negociada que en su momento se haga con Rusia y señala asimismo la posibilidad de solapamiento con la de Canadá en su día y una hipotética de los Estados Unidos (al no ser aún parte de la CNUDM, tendría que pasar por el trámite largo y complejo de serlo para llegar a la CLPC). 
- Canadá solo ha presentado una reclamación parcial de plataforma continental extendida relativa al Océano Atlántico el 6 de diciembre de 2013. Dados sus ambiciosos objetivos, todo hace sospechar que su solicitud de plataforma continental extendida en el Ártico será muy extensa y lo más probable es que se solape con la de la Federación de Rusia, Dinamarca y Estados Unidos.

- En un Acuerdo Provisional de 2006 (Agreed Minutes) concluido entre Islandia, Noruega y Dinamarca (Islas Feroe), los tres Estados establecen un principio de acuerdo sobre cómo proceder en el Mar de Noruega con sus peticiones solapadas de plataforma continental extendida, estableciendo un acuerdo tripartito que, para culminarse, precisa que la labor recomendatoria de la CLPC se termine.

- Noruega presentó su solicitud de plataforma continental extendida ante la CLPC en 2006, relativa al Loophole en el Mar de Barents, la Cuenca Nansen Oeste en el Océano Ártico y el Banana Hole en el Mar de Noruega, y desde abril de 2009 ha sido el primer país en obtener recomendaciones de la CLPC.

- Estados Unidos no es parte de la CNUDM y, por tanto, no puede entrar en el proceso de la CLPC. No obstante, la política norteamericana respeta los fundamentos del art. 76 de la CNUDM. Caben varias posibilidades: a) si los Estados Unidos delimitan su plataforma continental extendida sin el beneplácito de la CLPC, pueden encontrarse con la oposición de terceros que no respeten tal acto unilateral como válido; $b$ ) ante tal contingencia, los Estados Unidos se plantean pasar a ser parte de la CNUDM; c) cabría la posibilidad de llegar a un acuerdo negociado de límites con sus contrapartes (tal y como prevé en último término los arts. 76.8 y 76.10 de la CNUDM).

7. Las escasas controversias territoriales en el espacio ártico, los múltiples acuerdos, soluciones consensuadas o respeto a decisiones judiciales en lo que se refiere a las controversias marítimas, revelan que el Ártico ha funcionado como un espacio de cooperación pacífica. Por el momento, la actividad política que rodea a las reclamaciones de plataforma continental extendida en el Ártico, hace pensar más en invitaciones a la negociación conjunta de límites en zonas de solapamiento de dichas plataformas, que a agresivas proclamas soberanistas.

Elena CONDE PÉREZ

Universidad Complutense de Madrid http://dx.doi.org/10.17103/redi.68.1.2016.4a.04

\section{LA SENTENCIA DEL TRIBUNAL EUROPEO DE DERECHOS HUMANOS EN EL CASO VASILIAUSKAS C. LITUANIA (GS): EL GRUPO PROTEGIDO EN EL CRIMEN DE GENOCIDIO Y SU LESIÓN EN EL MARCO DEL ART. 7 DEL CONVENIO EUROPEO PARA LA PROTECCIÓN DE LOS DERECHOS Y DE LAS LIBERTADES FUNDAMENTALES}

1. Previo a cualquier análisis sobre la Sentencia Tribunal Europeo de Derechos Humanos (TEDH) en el caso Vasiliauskas c. Lituania [GS] (núm. 35343/05, Sentencia de 20 de octubre de 2015), es importarte recordar que la trágica historia de las Repúblicas Bálticas a partir de la Segunda Guerra Mundial permite comprender, en gran parte, el modo en que recogieron en sus Códigos Penales el delito de genocidio tras su independencia de la Unión Soviética. Aunque la concreta regulación en estos tres Estados no ha sido idéntica, a grandes rasgos puede afirmarse que han compartido un carácter expansivo que favorecía la calificación de genocidio de los crímenes cometidos en aquella época, y muy especialmente de los perpetrados durante la ocupación soviética. En el asunto que ahora interesa, de hecho y por si pudiera quedar 
alguna duda, la primera norma lituana al respecto, de 9 de abril de 1992, indicaba expresamente en su art. 2 que los asesinatos, torturas y deportaciones de habitantes de Lituania cometidos en la ocupación nazi y soviética se considerarían un crimen de genocidio tal y como lo define el Derecho internacional. En otros casos, como el Código Penal estonio de 2001, se optó por incluir junto a los grupos protegidos que figuran en la Convención para la Prevención y la Sanción del Delito de Genocidio, a quienes «resisten la ocupación»; previsión que no existía como tal en el posterior Código Penal lituano de 2003, que no obstante y de forma similar a la normativa letona, sí incluía en su art. 99 a los grupos «sociales o políticos» entre ellos.

2. Esta breve introducción nos dirige, en primera instancia, hacia uno de los temas más intensamente debatidos desde la misma redacción de la Convención contra el Genocidio y hasta la fecha, cual es, el conocido como "genocidio político». Es decir, si el exterminio de grupos políticos constituye, o no, un crimen de genocidio. De hecho, el demandante en el caso que examinamos - miembro del Ministerio de Seguridad del Estado y después de la no menos funesta KGB - había sido condenado por el tribunal regional de Kaunas, en febrero de 2004, por haber participado en 1953 en el exterminio de los habitantes de Lituania que pertenecían a «un grupo político separado» que se resistía a la ocupación soviética; crimen que fue calificado como genocidio. Ahora bien, poco después el tribunal de apelaciones precisó sobre lo anterior que los miembros de ese grupo tenían al mismo tiempo la condición de representantes de la nación lituana, es decir, de un "grupo nacional»; concluyendo, en suma, que los partisanos lituanos debían entenderse como un grupo no solo político, sino también a nacional y/o étnico. Es decir, dos de los grupos protegidos que expresamente figuran en la Convención contra el Genocidio. Por su parte y en lo que aquí nos ocupa, en febrero de 2005 el Tribunal Supremo sostendría que los partisanos encarnaron la resistencia de la «nación lituana» contra la ocupación soviética. Años después, el Tribunal Constitucional (re)formularía lo resumido indicando que, de acuerdo con las normas internacionales universalmente reconocidas, las acciones llevadas a cabo contra ciertos grupos políticos y sociales lituanos podían ser consideradas genocidio si tenían como objeto la destrucción de quienes representaban una parte importante de la nación lituana, amenazando así a la misma supervivencia de toda ella [Vasiliauskas c. Lituania (GS), párrs. 30-40 y 56-63].

De este modo, de la mano de los conceptos de «grupo político» y de extermino «parcial o en parte» de un «grupo nacional», fueron dos las cuestiones que debió enfrentar la Gran Sala del TEDH en el caso Vasiliauskas. No atendiendo a su configuración o contenido actuales, sino a la consideración del genocidio en 1953; esto es, como ya dijimos, el año en que se cometieron los hechos concretos. Y es que a juicio del demandante, en cualquiera de los dos casos lo resumido había supuesto una violación del art. 7 del Convenio Europeo para la Protección de los Derechos y de las Libertades Fundamentales (CEDH); en tanto que en esencia, se le había aplicado una tipificación del genocidio que excedía de lo que el Derecho internacional considerada como tal en aquel entonces. A este respecto, valga adelantar entonces que además de lo dicho, sería un elemento clave la general exigencia mantenida por el TEDH bajo lo que ha venido denominando "condiciones cualitativas», como las de accesibilidad y previsibilidad. Expresado en términos básicos, se trataría de que la aplicación del delito en cuestión ha de ser previsible para el sujeto [véase, por ejemplo, Korbely c. Hungría (GS), núm. 9174/02, Sentencia de 19 de septiembre de 2008, párr. 70].

3. Como es sabido, no ha sido esta la primera vez en que el TEDH ha abordado la delimitación del crimen de genocidio (véase Jorgic c. Alemania, núm. 74613/01, 
Sentencia de 12 de julio de 2007); tampoco la aplicación del art. 7.2 del CEDH a escenarios posteriores a la Segunda Guerra Mundial (consúltense, Kolk y Kislyiy c. Estonia, núms. 23052/04 y 24018/04, Decisión de 17 de enero de 2006, y Penart c. Estonia, núm. 14685/04, Decisión de 24 de enero de 2006). Sobre este segundo particular, tras estas dos decisiones, ciertamente la Gran Sala asumió una postura más restrictiva [véase especialmente, Kononov c. Letonia (GS), núm. 36376/04, Sentencia de 17 de mayo de 2010]; pero, en cualquier caso, en la Sentencia Vasiliauskas este asunto tuvo un protagonismo insignificante, siendo ventilado en apenas unos párrafos (en general, párrs. 187-190, que en realidad solo refieren a la posición anterior de la Gran Sala). Por ello, en esta oportunidad no entraremos en esta interesante cuestión general.

4. Analizando entonces el examen que realizó el TEDH sobre el crimen de genocidio, cabe también hacer una distinción a efectos expositivos, siguiendo lo señalado supra. En primer lugar, en lo que respecta al "genocidio político», la posición de la Gran Sala se apoyó singularmente en decisiones cercanas como la del Tribunal Internacional de Justicia, esto es, en la afirmación de que ya en el mismo proceso de redacción de la Convención contra el Genocidio, fue capital la identificación positiva de los grupos con características específicas para decidir qué grupos se iban a incluir y cuáles, como los grupos políticos, quedarían excluidos [Caso Relativo a la Aplicación de la Convención para la Prevención y la Sanción del Delito de Genocidio (Bosnia-Herzegovina c. Serbia y Montenegro), ICJ Reports 2007, párr. 194]. Agregando que todas las normas convencionales posteriores - hasta el Estatuto de la Corte Penal Internacional- no se habían separado de lo anterior; con lo que aunque algunos Estados hubieran decidido criminalizar el genocidio de un grupo político en sus leyes nacionales, no cabía entender en ningún caso que en 1953 ello fuese así de conformidad al Derecho internacional — convencional o general- [Vasiliauskas c. Lituania (GS), párrs. 170-175].

En este punto y en el asunto de fondo, entre las diversas posiciones críticas siempre cabría recordar, a modo de síntesis, interrogantes como aquel que entre nosotros se formulase en 1951; esto es: "¿Por qué [...] los grupos políticos de un país pueden ser exterminados sin que los autores de tales hechos aparezcan incriminados como genocidas?» (MIAJA DE LA MuELA, A., «El genocidio, delito internacional», REDI, 1951, núm. 2, pp. 376-377). No obstante, la conclusión ofrecida por el TEDH fue la generalmente admitida, y de hecho y a tenor de los votos particulares a la sentencia, no planteó discrepancia mayor.

5. Muy diferente fue lo que podemos considerar como segunda cuestión, no solo singularmente más compleja sino especialmente polémica en lo particular del caso, pues puede decirse que partió al tribunal casi en dos bloques. En lo jurídico, su esencia cabe dirigirla al debate acerca de los criterios que permitan fijar los límites de la parte del grupo cuya destrucción se pretende (FERnández PaCheCo, C., El genocidio en el Derecho Penal Internacional, Valencia, Tirant lo Blanch, 2011, pp. 179-193). Particular que enlaza con el mismo sentido de la formulación «destruir en todo o en parte» (Schabas, W. A., Genocide in International Law: The Crime of Crimes, Cambridge, 2. a ed., Cambridge University Press, 2009, pp. 273 y ss.); y que conduce hasta la propia concepción general del bien jurídico protegido y de su lesión; es decir, hasta el debate acerca de si la destrucción del grupo debe ser entendida en una dimensión física o biológica (GIL GIL, A., Derecho penal internacional. Especial consideración del delito de genocidio, Madrid, Tecnos, 1999, pp. 160 y ss.) o también social como mantiene, por ejemplo, parte de la doctrina alemana remitiéndose a la idea original de Lemkin (Werle, G. y Jessberger, F., Principles of International Criminal Law, Oxford, 3. a ed., 
Oxford University Press, 2014, p. 318). En lo más concreto y de su lado, nos enfrentaríamos también a lo que se ha calificado como la "mayor controversia» en este ámbito: la interpretación del elemento normativo «grupo nacional» (OllÉ SeSÉ, M., Justicia universal para crimenes internacionales, Madrid, La Ley, 2008, p. 491).

6. Con todo, la tesis sostenida por nueve de los 17 jueces de la Gran Sala vino a mantener que, en atención a los trabajos preparatorios y a la finalidad de la Convención contra el Genocidio, la mención de su art. II (la intención de destruir en parte a un grupo nacional, en este caso) solo cabía entenderla como referida a criterios cuantitativos, esto es, a la voluntad de exterminar una parte sustancial de grupo —en términos numéricos-. En este punto, obviamente el TEDH era consciente del conjunto de decisiones judiciales — cuya gran parte cita- que han puesto el acento en los criterios cualitativos, esto es, en lo que se suele conocer como la intención de destruir a una «parte prominente o significativa» del grupo. Al respecto, conviene apuntar que, al menos en mi opinión, parte de esta jurisprudencia es un tanto confusa en lo que se refiere a la distinción y/o relación entre la parte del grupo -o subgrupo significativo o prominente- y el grupo en su totalidad, pero dentro del espacio ahora disponible, baste ilustrar esta segunda postura con un par de referencias.

7. La primera, muy similar a la que suele considerarse como su inicial plasmación escrita (Doc. ONU S/1994/674), la del Tribunal ad hoc para la ex Yugoslavia. A saber: si no se cumple el criterio cuantitativo, la intención de destruir «en parte» puede establecerse si hay pruebas de que la destrucción se ha dirigido a una parte significativa del grupo, tal como sus líderes; siendo importante en este sentido, que la eliminación de estas personas tenga un impacto sobre la supervivencia del grupo como tal (Fiscalía c. Sikirica, IT-95-8, Sentencia de 3 de septiembre de 2001, párrs. 7677). La segunda, más reciente y seguramente algo más matizada, la del Tribunal Internacional de Justicia, que recordó en lo que nos ocupa que: «Account must also be taken of the prominence of the allegedly targeted part within the group as a whole» [Caso Relativo a la Aplicación de la Convención para la Prevención y la Sanción del Delito de Genocidio (Croacia c. Serbia), ICJ Reports 2015, párr. 142].

Ahora bien, para la mayoría del TEDH lo determinante fue que esta interpretación, sobre cuyo acierto no se manifestó expresamente, era muy posterior a 1953. De tal suerte que a su juicio no resultaba posible entender que el exterminio de aquellos lituanos que se oponían a la ocupación soviética fuera encuadrable como una serie de hechos dirigidos a destruir (parcialmente) al grupo nacional lituano. Resultando que el demandante no podría haber previsto entonces que el asesinato de los partisanos lituanos podría constituir un genocidio de los nacionales de Lituania; ni siquiera con la ayuda de un abogado, aclaró. A todo ello se añadió que además y en cualquier caso, incluso si la posterior interpretación cualitativa de los tribunales internacionales estuviera ya establecida y fuera previsible en 1953, los tribunales lituanos no habían demostrado suficientemente en lo fáctico, porqué o sobre qué base en aquel año los partisanos lituanos constituían una parte importante del «grupo nacional» [Vasiliauskas c. Lituania (GS), párrs. 165-186].

Esta última valoración fue singular y duramente criticada en votos disidentes como el del Juez Kuris. Pero en la cuestión jurídica general, la minoría reconocería que en 1953 no existía un desarrollo jurisprudencial acerca del significado de la frase "destruir en parte», si bien, esgrimió algo cuyo sustento fundamental conviene citar: «The fact that judicial interpretation of the 1948 Genocide Convention took time to develop cannot in itself mean that genocide did not occur prior to such interpretation" (voto disidente de los Jueces Villiger, Power-Forde, Pinto de Albuquerque y Kuris, 
párr. 18). La idea capital, que como tal aparece en el voto disidente de la Juez Ziemele (párr. 17), podría resumirse en que las decisiones judiciales que vinieron a explicitar lo antes dicho, no se corresponderían con nuevas interpretaciones de la Convención contra al Genocidio, en el sentido de incorporar nuevos elementos que no estaban presentes en ella, sino que se dieron en aquellos años porque, en fin, fue entonces cuando se abordó este crimen en sede judicial. Y a partir de ello, consideraron también infundada la conclusión de que resultase imposible para el demandante prever que estaba cometiendo un crimen de genocidio. Es decir, en lo más concreto, la posición fue que en tanto que en aquel mismo 1953 el demandante había declarado que como agente del Ministerio de Seguridad del Estado compartía el objeto de exterminar a los miembros de la resistencia nacionalista lituana [Vasiliauskas c. Lituania (GS), párr. 18], era probable que «un asesor legal independiente» le hubiera advertido de que ello tenía las características esenciales del crimen de genocidio (voto disidente de los Jueces Villiger, Power-Forde, Pinto de Albuquerque y Kuris, párr. 30).

8. Algunos autores han sostenido que la posición defendida por la mayoría del TEDH responde a una suerte de "evaluación estricta» sobre el requisito de la previsibilidad, avanzando que de ello pueden derivarse diversos problemas en otros casos o instancias (SKANDER GALAND, A., "The Strasbourg Court Destroys "in part" The Hague's Case Law on Genocide», en https://kuremer.ku.edu.tr/en/strasbourg-court-destroys-part-hagues-case-law-genocide). Ciertamente, no cabe referir la crítica hacia la defensa de interpretaciones excesivamente expansivas cuando se trata de las importantes garantías que implica el art. 7 del CEDH, pero la postura del tribunal plantea no pocas cuestiones espinosas. Sin duda, desde una dimensión histórica y/o política (véase, por ejemplo, Human Rights Monitoring Institute, «Is Killing Freedom Fighters Genocide? Lithuania Fails to Prove Claim», en http://www.liberties.eu/en/news/ lithuania-genocide-political-group), aspecto que no se debe minusvalorar si se presta atención al modo en que esta sentencia ha sido interpretada por algunos medios de comunicación rusos (véase, por ejemplo, SHAmshiEv, A., "The European Court is Against the Lithuanian National Myth», en http://www.rubaltic.ru/articles/lithuaniannational-myth-27102015/); pero también y especialmente en lo jurídico. Limitémonos ahora a destacar una de ellas: Si en 1953 aún no estaban establecidos los criterios cualitativos en lo que al genocidio respecta, ¿cuándo quedaron así determinados? Pues si la respuesta fuera que no hasta finales de la década de los noventa del siglo pasado, parece evidente que a todas las personas a las que se les hubiesen aplicado por crímenes cometidos con anterioridad, se les habría violado el mismo derecho que al demandante en el caso Vasiliauskas...

Javier CHINCHÓN ÁLVAREZ Universidad Complutense de Madrid http://dx.doi.org/10.17103/redi.68.1.2016.4a.05

\section{LA CRISIS MIGRATORIA Y LA REINSTAURACIÓN DE LOS CONTROLES DE LAS FRONTERAS INTERIORES EN EL ESPACIO SCHENGEN}

1. La denominada crisis de los refugiados ha implicado el traslado de centenares de miles de personas desde zonas en conflicto, especialmente, aunque no exclusivamente, procedentes de Siria, Iraq, Afganistán y Libia hacia la Unión Europea (UE) en busca de protección internacional. Este desplazamiento se realiza sorteando innumerables obstáculos, en condiciones lamentables y con grave riesgo para las vidas de los participantes. La magnitud de esta marea humana está afectando seriamente a la 
libre circulación de personas en el espacio Schengen (que en la actualidad comprende un total de 26 países: Islandia, Noruega, Liechtenstein y Suiza, además de todos los miembros de la UE excepto Reino Unido, Irlanda, Chipre, Croacia, Rumania y Bulgaria). Es conocido que desde su entrada en vigor el 26 de marzo de 1995, el Convenio de Aplicación del Acuerdo Schengen (CAAS) ha supuesto, para aquellos países que son parte contratante, la supresión de las inspecciones fronterizas a las personas que cruzan las fronteras interiores entre los Estados participantes y las ha trasladado a las fronteras exteriores.

Desde su creación se han planteado problemas respecto a la capacidad de algunos países para gestionar los flujos migratorios y se ha hecho patente la desconfianza respecto al control eficiente de las fronteras exteriores por determinados Estados miembros (en teoría Bulgaria y Rumania reúnen los requisitos para integrarse completamente en el espacio Schengen, pero el Consejo no se ha puesto de acuerdo para eliminar las inspecciones fronterizas con el resto de participantes). De todas formas, la dimensión del movimiento de personas es incomparable con cualquier situación anterior y no resiste analogía alguna. En efecto, según los datos suministrados por FRONTEX (http://frontex.europa.eu/trends-and-routes/migratory-routes-map/) entre los meses de enero y octubre de 2015, más de un millón de personas han cruzado la frontera exterior del espacio Schengen de forma irregular. De las cuales, 581.640 por la denominada ruta del Mediterráneo Oriental (provenientes de Turquía y con destino a Grecia, Bulgaria y Chipre); 502.018 que utilizan la denominada ruta de los Balcanes Occidentales (que tiene su origen por un lado, en los propios movimientos migratorios de los países balcánicos y, por otro, de migrantes de origen asiático que inicialmente entraron en la UE por Bulgaria y Grecia, provenientes de Turquía y cuyo destino es, principalmente, Hungría); y 140.705 por la ruta del Mediterráneo Central (desde el Norte de África, especialmente Libia, hacia Italia y Malta).

2. Esta corriente humana no se ha distribuido homogéneamente entre los países de la UE sino que se ha dirigido específicamente hacia un grupo concreto de Estados, aquellos que conceden unas mejores condiciones de acogida a los solicitantes de asilo; entre estos destacan los siguientes: Alemania (entre el 1 de enero y el 13 de octubre de 2015 ha registrado como solicitantes de asilo a, aproximadamente, 641.500 nacionales de terceros Estados) y Suecia (que, aproximadamente, en el mismo periodo de tiempo ha acogido 112.264 peticiones de asilo). El caso sueco es especialmente significativo atendiendo a su peso demográfico. Así para datos de 2014, Suecia, que acogió el 12,98 por 100 del total de las demandas en la UE, registraba una tasa de solicitudes de asilo de 8.432 por cada millón habitantes. Para contextualizar las cifras, Alemania en el mismo año, acogió un 32,36 por 100 del total, que significaba una tasa de 2.511 solicitudes por cada millón; Italia un 10,31 por 100 , con una tasa de 1.063 por millón; Francia un 10,26 por 100, con una tasa de 977 por millón y Hungría que recibiendo un 6,83 por 100 del total, también realizaba un esfuerzo mayúsculo al tener una tasa de 4.331 solicitantes por millón de habitantes. En el otro extremo se encuentran países que tienen una tasa de solicitudes de asilo por millón de habitantes extremadamente reducida, como España que acogiendo al 0,90 por 100 del total de solicitantes, le correspondía una tasa de 121 o Estonia, con una tasa de 118 por millón de habitantes. Cierra la lista Portugal con tan solo 43 solicitudes por millón de habitantes... (http://ec.europa.eu/dgs/home-affairs/e-library/multimedia/infographics/ index_en.htm\#0801262488c180fa/c_9).

Esta desproporción entre los Estados miembros y esta heterogeneidad de tratamiento de las solicitudes puede derivar (y de hecho parece ser que así se está produ- 
ciendo) en una reducción de la protección concedida por los países más generosos y solidarios.

3. La normativa comunitaria que regula el derecho de asilo no está satisfaciendo las necesidades actuales. El Reglamento Dublín (Reglamento 604/2013 del Parlamento Europeo y del Consejo, de 26 de junio, aplicable desde el 1 de enero de 2014) que establece los criterios y los mecanismos para determinar el Estado miembro responsable del examen de la solicitud de protección internacional, y que, en esencia, implica que la responsabilidad de examinar las solicitudes recaiga en el Estado miembro que haya desempeñado el papel más preponderante en la entrada del solicitante en la UE no está funcionando adecuadamente. Adicionalmente, los Estados no están contribuyendo a la correcta aplicación de la normativa comunitaria. La Comisión ha iniciado una batería de recursos contra los Estados miembros por el incumplimiento de la normativa comunitaria que regula Sistema Europeo Común de Asilo (SECA). Efectivamente, entre el 23 de septiembre y el 10 de diciembre de 2015, ha interpuesto una cuarentena de recursos contra Estados miembros por una errónea, o por ausencia de, transposición de la normativa comunitaria que integra el SECA (que se añaden a la treintena de asuntos pendientes de resolución ante el Tribunal de Justicia de la Unión Europea). En concreto, merece destacarse que la Comisión se ha dirigido contra 19 Estados (todos menos Finlandia, Italia, Países Bajos, Portugal, Eslovaquia y Croacia, ya que Irlanda, Reino Unido y Dinamarca no están vinculados por la misma) por la posible infracción de la Directiva que regula las condiciones de acogida de los solicitantes de protección internacional (Directiva 2013/33 del Parlamento Europeo y del Consejo, de 26 de junio, exigible desde el 21 de julio de 2015); y ha emitido decisiones de incumplimiento contra 18 Estados (con excepción de Austria y los anteriormente mencionados) por la posible contravención de la Directiva sobre los procedimientos comunes para la concesión o la retirada de la protección internacional (Directiva 2013/32 del Parlamento Europeo y del Consejo, de 26 de junio, aplicable desde el 21 de julio de 2015).

4. La imposibilidad de regular los flujos y de asumir proporcionalmente el volumen de refugiados ha provocado que algunos Estados miembros hayan reinstaurado las inspecciones fronterizas internas restableciendo los obstáculos al cruce de personas en las fronteras entre los países Schengen. Esta posibilidad está prevista tanto en el CAAS como en el denominado Código de Fronteras Schengen (el Reglamento 562/2006 del Parlamento Europeo y del Consejo, de 15 de marzo, por el que se instituye un Código comunitario de normas para el cruce de personas por las fronteras, modificado en diversas ocasiones, la última de las cuales mediante el Reglamento $1051 / 2013$, de 22 de octubre).

La reintroducción de obstáculos físicos a la libre circulación de personas requiere la satisfacción y el cumplimiento de varias condiciones. En primer lugar, el restablecimiento de los controles fronterizos tiene un carácter excepcional, es un recurso que debe invocarse como última instancia, y su ejercicio está limitado en el tiempo, se concede por un plazo máximo de treinta días, susceptible de ser ampliado. En segundo lugar, el motivo de la restauración de los controles debe obedecer a la existencia de una amenaza grave para el orden público o para la seguridad interior del Estado miembro, y la duración de las restricciones no puede exceder a la estrictamente necesaria para responder la amenaza grave.

En la práctica, durante los veinte años de funcionamiento del espacio Schengen, los países han acudido de forma extraordinaria a esta posibilidad. En pocas ocasiones se han impuesto los controles fronterizos; y cuando se ha hecho, en la inmensa mayo- 
ría de las ocasiones, se ha justificado por motivos relacionados con manifestaciones de carácter político (reuniones de altos mandatarios en diversos foros internacionales como las celebradas por el Consejo Europeo o reuniones de un nivel de participación equivalente, visitas de representantes políticos...) y siempre que ello ha tenido lugar se han reintroducido por periodos cortos de tiempo y para unos puestos precisos y concretos. De hecho, y a título ilustrativo, desde la entrada en vigor del Código de Fronteras Schengen en 2006 hasta el año 2014, inclusive, tan solo se recuperaron los controles en 35 oportunidades. En la actualidad esta situación ha variado drásticamente, durante el segundo semestre del 2015 se han restituido en once ocasiones y media docena de países del espacio Schengen han repuesto las inspecciones fronterizas por motivos relacionados con un flujo excesivo de personas transitando sus fronteras. Tal es el caso de Noruega (desde el 26 de noviembre hasta el 26 de diciembre de 2015), Austria (desde el 16 de septiembre, que ha ido renovando y hasta el 15 de febrero de 2016), Alemania (desde el 13 de septiembre y que ha ido renovando periódicamente, y en la actualidad se mantiene hasta el 13 de febrero de 2016), Suecia (desde el 12 de noviembre hasta el 11 de diciembre de 2015) y Malta (desde el 9 de noviembre hasta el 31 de diciembre de 2015) que lo imponen en todos los puestos fronterizos con otros Estados participantes. Hungría (desde el 17 al hasta 26 de octubre de 2015) y Eslovenia (desde el 17 de septiembre hasta el 16 de octubre de 2015) solo lo restablecieron en determinados puestos fronterizos terrestres comunes. A esta situación de obstaculización de la libre circulación de personas, se debe de añadir el aumento y la generalización de los controles policiales en Francia. Estos, que evidentemente, están permitidos en el espacio Schengen (siempre y cuando no sean equivalentes a una inspección fronteriza), han adquirido un carácter sistemático en los aledaños de numerosos puestos fronterizos terrestres de Francia con sus vecinos europeos, tras los terribles atentados ocurridos el 13 de noviembre en París.

Este cúmulo de circunstancias ha proyectado una visión pesimista sobre el mantenimiento de la libre circulación de personas y está planeando la posibilidad de suspender la aplicación del espacio Schengen, por la manifiesta incapacidad de sus Estados participantes para gestionar la crisis migratoria. En este sentido, cabe recordar que el Código de Fronteras Schengen (tras la revisión operada por el Reglamento 1051/2013) permite a la Comisión recomendar la restitución de las inspecciones en las fronteras interiores de un Estado miembro con el resto de los países del espacio Schengen cuando observe insuficiencias en el control de las fronteras exteriores, detecte deficiencias graves y persistentes en su vigilancia o en la aplicación correcta de los procedimientos de retorno, y ello suponga una amenaza grave para el orden público o para la seguridad interior de la Unión Europea o de un Estado miembro. En principio el plazo máximo de la excepción se circunscribe a seis meses, que pueden ser prorrogados si las carencias no se han solucionado hasta una duración máxima de dos años (art. 26).

5. A todo ello la UE ha empezado dar pasos para intentar mitigar la tensión migratoria, centrándose en fortalecer las relaciones que se mantienen con terceros Estados, origen o tránsito del movimiento de personas. En este sentido, especialmente significativo es la (re)intensificación y relevancia que han adquirido las relaciones con Turquía, y que han cristalizado en la aprobación de un Plan Conjunto de Acción que, entre otras cuestiones, conducirá en un futuro inmediato a la liberalización de visados entre la UE y Turquía y a la plena aplicación del acuerdo de readmisión entre ambos para el mes de junio de 2016 (Doc. EUCO 26/15, de 16 de octubre de 2015). En este contexto de acentuación de las relaciones, se celebró, el 29 de noviembre de 2015, una reunión informal con los jefes de Estado o de Gobierno de la UE con Turquía, donde se reiteraba la necesidad de cooperación mutua en diversos ámbitos y de 
forma especial se declaraba la reactivación de las negociaciones con Turquía para su adhesión a la Unión; todo ello con el compromiso europeo de proveer de asistencia humanitaria de «forma continua e inmediata» a Turquía para ayudar a los sirios que, temporalmente, se encuentran desplazados en territorio turco (European Union, Statements and Remarks, núm. 870/15, de 29 de noviembre de 2015).

Turquía no ha sido el único país al cual dirigirse para intentar reducir el continuo flujo de personas; la UE también está dando pasos para disminuir la corriente migratoria mediante la articulación de un conjunto de actuaciones dirigidas a los países africanos. Un buen ejemplo lo constituye la reunión de los jefes de Estado o de Gobierno de África y de la UE sobre migración celebrada en La Valetta (Malta) el 12 de noviembre de 2015. En esta se adoptó un Plan de Acción que incluía, entre otras acciones, la creación de un Fondo de Emergencia, que debería financiar proyectos en los países africanos más frágiles y vulnerables. Todo ello debería confirmar que la mejor estrategia para reducir la presión migratoria es la que incluye el diálogo y la cooperación con los países de origen y de tránsito.

6. En definitiva, la denominada crisis de los refugiados ha puesto de manifiesto la endeblez de las estructuras del SECA y la dificultad de articular una política de asilo común entre los Estados miembros de la UE. La crisis ha constatado también que la solidaridad dentro de la UE no es un valor en alza, y que el diferente trato que conceden los Estados miembros a los solicitantes de asilo ponen en riesgo el funcionamiento de la libre circulación de personas comunitaria. Paralelamente, esta diferencia de trato está generando, lamentablemente, una «competencia a la baja» en la prestaciones concedidas y un endurecimiento en las condiciones de concesión; todo ello en un contexto político, en muchos países miembros, que no favorece la solidaridad con los migrantes originarios de países del Oriente Medio y el Norte de África. En cualquier caso, la existencia de la libre circulación de personas sin inspecciones fronterizas entre los Estados miembros tal y como la entendemos en la actualidad, podría estar en serio peligro. 